\title{
Laboratory analysis of cyanobacterial toxins and bioassays
}

\author{
Linda A. Lawton, James S. Metcalf, \\ Bojana Žegura, Ralf Junek, Martin Welker, \\ Andrea Törökné, and Luděk Bláha
}

\section{CONTENTS}

$\begin{array}{ll}\text { Introduction and general considerations } & 747\end{array}$

$\begin{array}{lll}14.1 & \text { Sample handling, storage and shipping } & 750\end{array}$

14.1.1 Safety 750

14.1.2 Sample processing for storage $\quad 750$

14.1.3 Sample storage and shipment $\quad 752$

$\begin{array}{lll}\text { 14.1.4 Traceability } & 752\end{array}$

14.2 Generic methodologies used in cyanotoxin analysis 753

14.2.1 Sample extraction for analysis 753

14.2.1.1 Solid-phase extraction (SPE) 753

14.2.2 Enzyme-Linked Immunosorbent Assay (ELISA) 754

14.2.3 High-performance liquid chromatography (HPLC) 756

14.2.3.1 Ultra-performance liquid chromatography (UPLC) 758

14.2.4 Liquid chromatography with mass spectrometry (LC-MS) $\quad 758$

14.2.5 Selecting an analytical system 759

14.3 Quantification of microcystins and nodularins 761

14.3.1 Extraction methods for microcystins and nodularins 761

14.3.1.1 Cyanobacterial cells 761

14.3.1.2 Water samples $\quad 762$

14.3.1.3 Tissue samples $\quad 763$

14.3.2 Quantification of microcystins and nodularins
by biochemical methods

14.3.2.1 Quantification by protein phosphatase inhibition assay $\quad 764$

14.3.2.2 Immunoassays for microcystin and nodularin detection $\quad 765$

14.3.3 Instrumental analytical methods for microcystins and nodularins $\quad 765$

14.3.3.1 Analysis of microcystins and nodularins by HPLC-PDA $\quad 765$ 
14.3.3.2 Analysis of microcystins and nodularins by LC-MS(MS)

14.4 Quantification of CYLINDROSPERMOPSINS 768

14.4.1 Extraction of cylindrospermopsins $\quad 768$

14.4.1.1 Cyanobacterial cells $\quad 768$

14.4.1.2 Water samples $\quad 768$

14.4.1.3 Tissue and urine samples $\quad 769$

14.4.2 Quantification of cylindrospermopsins by ELISA 769

14.4.3 Instrumental analytical methods for

cylindrospermopsins $\quad 770$

14.4.3.1 Analysis of cylindrospermopsins by HPLC-PDA 770

14.4.3.2 Analysis of cylindrospermopsins by LC-MS(MS) 771

14.5 Quantification of ANATOXINS 771

14.5.1 Extraction of anatoxins $\quad 772$

14.5.1.1 Cyanobacterial cells $\quad 772$

14.5.1.2 Water samples $\quad 772$

14.5.1.3 Tissue samples 772

14.5.2 Quantification of anatoxins by ELISA 772

14.5.3 Instrumental analytical methods for anatoxins $\quad 773$

14.5.3.1 Analysis of anatoxins by HPLC-PDA 773

14.5.3.2 Analysis of anatoxins by LC-MS(MS) 773

14.6 Quantification of saxitoxins 774

14.6.1 Extraction of saxitoxins 774

14.6.1.1 Cyanobacterial cells $\quad 774$

14.6.1.2 Water samples $\quad 775$

14.6.1.3 Tissue samples $\quad 775$

14.6.2 Quantification of saxitoxins by biochemical methods 775

14.6.2.1 Quantification of saxitoxins by ELISA 775

14.6.3 Instrumental analytical methods for saxitoxins $\quad 776$

14.6.3.1 Prechromatographic oxidation and liquid chromatography with fluorescence detection $\quad 776$

14.6.3.2 Analysis of saxitoxins by LC-MS/MS 776

14.7 Detection and quantification of anatoxin-a(s) 777

14.8 Methods for synchronous detection of multiple types of cyanotoxin $\quad 777$

14.8.1 Multiplex antibody systems $\quad 777$

14.8.2 Multi-cyanotoxin analytical methods $\quad 778$

14.9 Future developments 778

14.10 Bioassays and their use in the survey of toxic cyanobacteria $\quad 779$

14.10.1 Insights into interpretation of toxicity results $\quad 780$

14.10.2 Bioassays in the assessment of toxic cyanobacteria 781

14.10.2.1 Nonmammalian bioassays 782 
14.10.2.2 Mouse bioassay

14.10.3 In vitro assays for determining toxicity and genotoxicity

\section{INTRODUCTION AND GENERAL CONSIDERATIONS}

Cyanobacterial toxins or cyanotoxins are a diverse group of compounds with differing chemistries; hence, a single analytical method can rarely be used to evaluate all potential compounds. The general steps required to detect, identify, quantify and monitor the different classes of toxins do follow a common approach (Figure 14.1).

Before committing to a major cyanotoxin sampling campaign, it is important to evaluate the information and level of detail required to make appropriate management decisions (see also Chapters 11 and 12). Planning the work therefore is best done by a group including the different aspects involved, for example, field samplers, laboratory support, analysts, as well as

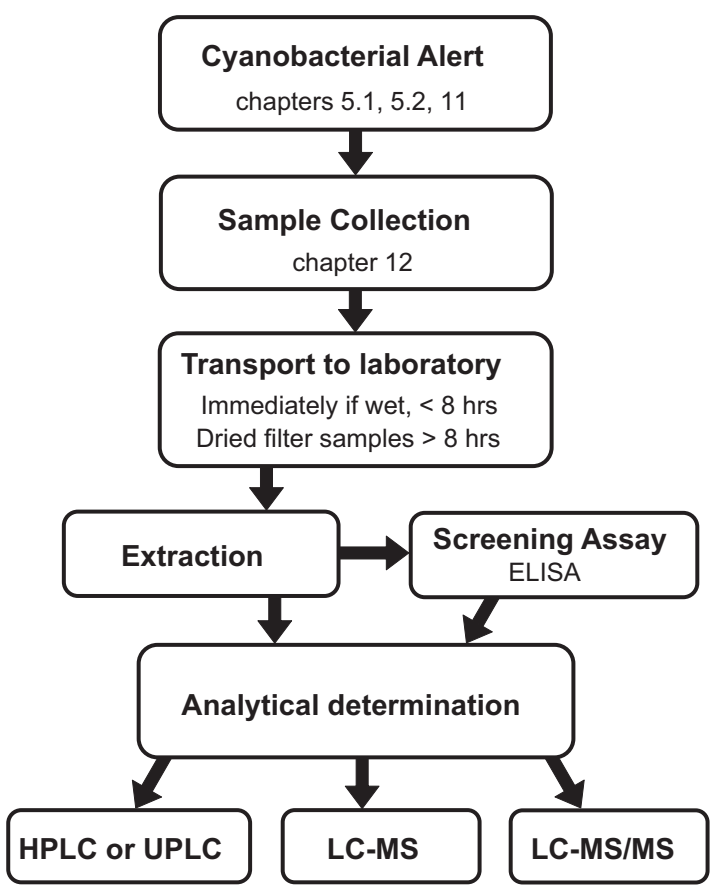

Figure 14.I General scheme from cyanobacteria alert (see Chapter 5) to analytical determination of cyanotoxin concentrations. 
managers leading the work, possibly in contact with the authority responsible for public health. This way a range of perspectives come together to design the most suitable and effective approach. An audit by others with expertise in the field (in-house or external) serves to ensure that all important areas have been considered and nothing essential is overlooked. Some of the key questions and topics which should be covered in planning and auditing are included in Checklist 14.1, and it is important to take time to make sure that all important requirements can be fulfilled.

The available methods for analysing cyanobacterial toxins are very diverse. The criteria for selecting the appropriate analytical method for a given monitoring programme include the consideration of reproducibility, sensitivity and selectivity (see Box 14.1) as well as factors such as the time to result, required training, capital investment and laboratory conditions needed, and consumable running costs per sample.

\section{BOX 14.I: PARAMETERS OF ANALYTICAL PERFORMANCE}

Before any analysis is done, it is important to understand the nature of the problem to be addressed and the type of data required. A number of terms are often used to describe the performance of an analytical method. Of these terms, the most important are accuracy, precision, sensitivity, repeatability and reproducibility. For any analytical method that is set up to quantify cyanotoxins, these parameters should be determined and well documented to support the validity of the resulting data.

Accuracy defines the closeness of measured amount of a compound in a sample to the true amount in the sample. The actual or true value has to be determined by a validated method using reference material.

Precision defines the closeness of repeated measurements of a single sample to each other. To achieve high accuracy of a method, it needs to be highly precise but high precision does not guarantee high accuracy because measurements could be biased by a systematic error.

Sensitivity defines the capability of a method to avoid false-negative results, that is, to detect a compound in a sample when it is present but to not give a result when the compound is absent. In practice, the higher the sensitivity, the lower the limit of detection.

Repeatability characterises the consistency of measured values obtained from a single sample by one person applying one method on one analytical system. To test repeatability generally includes all sample preparation steps, and usually a predetermined limit of variability is set in which the measured values should lie for the method to be accepted. 
Reproducibility characterises the consistency of measured values obtained from a sample by different persons on different analytical systems. Reproducibility of a method that is applied in different laboratories is preferably validated with interlaboratory comparison tests, where a single sample of known toxin content is split and analysed by different laboratories.

Exact definitions of these and further terms related to analytical chemistry can be found at http://goldbook.iupac.org/index.html

Trained staff are needed, especially to operate complex analytical systems, primarily for the establishment of methods for analytes not yet analysed in the particular laboratory and their initial validation phase. For routine analyses, modern analytical systems generally offer some degree of automation that can be made use of once a method has been established.

As a rule of thumb, the most sensitive and specific methods tend to be the most demanding ones in terms of investment (capital, method optimisation and validation), required personnel training and running costs - but often with a substantial delay of result delivery of hours to days. On the other hand, methods that are less sensitive and selective may deliver results very fast. This can be essential in situations where an analytical result is needed to trigger immediate management actions to mitigate risks, for example, in Alert Level Frameworks (see Chapters 5.1 and 5.2).

\section{CHECKLIST I4.I CYANOTOXIN DETECTION}

- Which toxin classes are to be analysed?

- From what type of samples (e.g., water, cells, tissue, sediments)?

- Does the detection have to be quantitative? If so, what detection limit is required?

- Do drinking-water samples need immediate quenching (e.g., sodium thiosulphate or ascorbic acid) to eliminate the continued action of oxidising agents like chlorine?

- What instrumentation and expertise is available (i) in-house or (ii) external?

- What capacity is available, that is, which number of samples can currently be analysed (including laboratory space, appropriate sample storage)?

- What training is needed - for sampling, for sample processing, for analysis and for data interpretation? How are the data going to be used and reported? 


\section{I SAMPLE HANDLING, STORAGE AND SHIPPING}

Following a sampling trip, the samples arriving in the laboratory need to be processed further for analysis or storage. Three aspects are important for sample handling and storage: safety, sample processing to ensure stability and traceability.

\section{I.I Safety}

Laboratory staff handling samples potentially containing toxic cyanobacteria and cyanobacterial toxins are potentially exposed to health hazards (see also section 5.2), and appropriate protective measures need to be implemented. These measures will be based on two aspects: implementing general safety measures for hazardous material defined in national and international occupational health and safety guidelines, and an assessment of the risk of exposure to toxic cyanobacterial material potentially given in the specific procedures to be carried out. Any staff member handling potentially toxic cyanobacterial samples has to be accordingly trained and equipped with adequate protective equipment. Depending on the work to be done, this protective equipment will range from standard laboratory coats, gloves and safety glasses to - where there is a risk of inhalation exposurebreathing masks (Stewart et al., 2009). For water samples taken in monitoring programmes, the quantities of toxins are generally low, that is, in the low microgram per litre range, likely posing no risk of intoxication. Nonetheless, skin and eye contact, inhalation and ingestion have to be avoided by wearing an appropriate safety wear. Risks of exposure tend to be higher if larger quantities of bloom material are handled, for example, for toxin purification, with toxin quantities potentially in the low milligram range. The highest risk of exposure to toxic material is likely through the handling of dried bloom material, that is, exposure to dust, requiring the wearing of a breathing mask and/or the handling of sample material in an exhaust hood. Powdery freeze-dried bloom material, often statically charged, easily escapes containment, and this may cause a risk of exposure not only during laboratory work but also for cleaning staff.

\section{I.2 Sample processing for storage}

Samples that are not analysed immediately upon arrival at the laboratory need to be stored properly to avoid degradation of the cyanotoxins to be quantified (see Figure 12.3). Generally, cyanobacterial toxins are rather stable compounds, and storage at $-20^{\circ} \mathrm{C}$ largely prevents degradation. As guidance, the stability - or breakdown - as described in Chapter 2 may serve as a first orientation for conducting stability testing under the actual conditions, including all steps in transportation, storage and shipping. Since 
degradation mostly occurs through microbial activity, lower temperatures generally increase stability.

However, simply freezing entire samples may not be appropriate for practical and analytical reasons. For example, when extracellular and intracellular toxins are to be analysed separately, this requires prior separation of both fractions, which can no longer be done once samples have been frozen. Therefore, sample processing steps may be required that allow a reliable and efficient preservation of samples or portions of samples for later analyses.

If the toxin content in the particulate fraction is to be analysed, cyanobacterial cells and other particulate material ("seston") are best collected on a filter, thus concentrating the sample for space-efficient storage. One criterion for the choice of the type of filter (glass fibre, membranes of different types, cellulose) is the appropriate pore size to retain cyanobacteria. As most toxigenic taxa occur in colonies or filaments, pore sizes $<2 \mu \mathrm{m}$ are generally acceptable. Smaller pore sizes may slightly increase retention efficiency but at the cost of more rapid clogging of the filters - which is a factor that determines to a large extent the time needed to process samples. Further, it is important that the filter material be compatible with the downstream processing, in particular with the extraction procedure to avoid the release of any compounds that interfere with the downstream analysis during the extraction step in organic solvents; also, it must not be dissolved by these solvents. A protocol for the handling of such samples needs to be validated and tested with negative controls, that is, filters through which pure water has been passed.

For the filtration step, the water sample is well mixed immediately before measuring a volume to be filtered, for example, with a calibrated cylinder, because even within a very short time (i.e., minutes), buoyant cyanobacteria can float to the top (and other phytoplankton can settle), potentially leading to biased analytical results. Preferably, the total volume to be filtered is portioned into several smaller volumes to avoid increasingly longer filtration times on a gradually clogged filter. The volume to be filtered for an individual sample depends on the density of cells - that can hence be highly variable - and on the detection limit of the downstream analytical procedure. For the latter, the extraction and concentration steps need to be considered.

The filter should hold only residual moisture before it is frozen for storage or processed further for analysis, respectively, as discussed in the following section.

Filtrates are used for the analysis of dissolved (i.e., extracellular) cyanotoxins. To produce larger volumes of particle-free samples, it may be helpful to use a combination of two filters, for example, a glass fibre filter to retain larger particles and a second filter with smaller pores to remove small particles. 


\section{I.3 Sample storage and shipment}

If filter samples are to be stored, they are folded loaded-face on loaded-face and placed in an appropriate container, for example, chemically inert reaction tubes or enveloped in aluminium foil and labelled correctly. For their long-term storage or shipment, it is advantageous to dry the loaded filters; otherwise, shipment on dry ice is recommended. Drying can be achieved by freeze drying, in a vacuum centrifuge or at moderate temperatures $\left(<80^{\circ} \mathrm{C}\right.$ for microcystins and cylindrospermopsins) in a drying oven when lyophilisation is not available (Welker et al., 2005). For the latter, stability tests are recommended to check whether the drying process (that may last for several hours) causes any degradation. It is generally good practice to test the stability of the samples under the chosen storage conditions with a series of identical samples that are analysed at the different processing steps and after varying storage times. Performing the extraction procedure in the storage tube can allow safe handling, reduce processing time and minimise the risk of sample confusion.

For the storage of particle-free filtrate or extract, toxin adsorption to labware may be relevant. A few studies on this issue show that microcystin congeners differ in their tendency to adsorb to materials (Hyenstrand et al., 2001; Kamp et al., 2016; Altaner et al., 2017). These studies cover only some of the possible combinations of materials, solvents and toxins, and it is recommended to test the material used in an individual laboratory under the actual sample processing procedures to assess suitability. Once labware of a particular material and manufacturer has been found appropriate, it should not be changed without corresponding verification.

Shipping of samples requires consideration not only of stability but also of compliance to legal aspects, in particular declaration rules for transborder shipments (see Metcalf et al. (2006) for an overview).

\section{I.4 Traceability}

It is critically important to label all field samples arriving in the laboratory in a way that allows the results to be tracked back to the sampling site and sampling date at a later point in time. Similar considerations also apply for individual steps in sample processing, dilution of standards and quality control (QC) samples. For certified laboratories, the traceability of samples and materials is essential and generally follows guidelines such as ISO 9001 (ISO, 2015). Although a thorough quality management system according to ISO 9001 may not be necessary for non-certified laboratories, some principles can be implemented to ensure proper sample management.

As outlined in Chapter 11, a first important point is the labelling of individual samples. Sample names need to be unique, not only for a recent set of samples but also with respect to all samples that are expected in the future in a given laboratory and in cooperating laboratories. A naming system is therefore best defined prior to sampling campaigns and followed by 
the entire staff. Whichever system of sample naming is agreed upon, it is important to register all samples received in a laboratory in a central repository that is in turn backed up regularly. As barcode labelling and reading is becoming affordable, the introduction of these respective systems is now an option. Furthermore, labels need to be stable, that is, lastingly attached to sample containers under the actual storage conditions. Especially when samples are stored in the freezer, adhesive labels or markings need to be tested for resilience to repeated freeze-thaw cycles.

\subsection{GENERIC METHODOLOGIES USED IN CYANOTOXIN ANALYSIS}

\subsection{Sample extraction for analysis}

Most cyanotoxins are retained in the cell-bound fraction of samples taken from waterbodies (Chapter 2). Only when cyanobacterial populations experience cell lysis, for example, in surface scums exposed to high temperatures and light intensities, substantial amounts of toxins are released to the surrounding water. An exception is cylindrospermopsin that can be released from viable cell and found in large proportions in the cell-free fraction (section 2.2 Box 5.1 and Chapter 10). Further, extraction and sample clean-up is of critical importance for the analysis of cyanotoxins in foods to avoid both under- and overestimating concentrations (see section 5.3.4).

To make cell-bound cyanotoxins accessible to chemical analysis, they need to be extracted from the cells with an appropriate solvent. The solvent needs to be selected to efficiently extract toxins from cells in a few (maximum of three) extraction cycles and needs to be compatible with downstream analytical methods. Extraction procedures for individual classes of toxins will be discussed in the respective sections.

There is no single method available that is suitable for extracting all classes of cyanotoxins; hence, it may be necessary to collect several samples or subdivide samples prior to processing (see Chapter 12).

\subsection{I.I Solid-phase extraction (SPE)}

While some immunoassay (ELISA) methods and LC-MS/MS (see below) may be sufficiently sensitive for monitoring in compliance with guideline values, trace analysis of cyanotoxins in water (i.e., concentrations below 1 $\mu \mathrm{g} / \mathrm{L}$ ) typically requires sample concentration using solid-phase extraction (SPE). This processing involves passing a known volume (typically 100$500 \mathrm{~mL}$ ) of a (particle-free) water sample through a solid-phase cartridge to concentrate dissolved cyanotoxins. SPE requires a vacuum manifold system, PTFE (polytetrafluorethylen) connectors and tubing (for a minimum adsorption of analytes) and a vacuum pump. The equipment for SPE can be 
used for different classes of cyanotoxin; however, specific cartridges need to be used which retain the cyanotoxin of interest. A large selection of ready-to-use SPE cartridges is available with different sorbent materials and varying sorbent volumes. Sorbent materials primarily differ in the degree of hydrophobicity and have to be selected in correspondence with the cyanotoxin of interest, for example, C18 for microcystins or graphitised carbon for highly hydrophilic cylindrospermopsins.

Filtering water prior to SPE is essential to minimise clogging of the cartridges. Nonetheless, during times of blooms, the higher load of very small particles may significantly increase loading times. In this case, it is advised to note the volume of sample that has already passed and discontinue the sample loading. Once the water sample has passed through the cartridge, a washing step follows before the toxin adsorbed on the cartridge is eluted in a small volume (typically 3-5 times the sorbent bed volume) of solvent into a collection tube (Figure 14.2). This can be analysed directly or further concentrated by drying to enhance the detectability. It is tempting to load as large a volume of water sample as possible to allow the detection of low levels of cyanotoxin; however, this is not always appropriate. Larger volumes can take many hours to load onto the cartridge and matrix contaminants are also being concentrated; hence, larger sample volumes increase matrix interference. Loading samples onto SPE cartridges can be time-consuming so it is wise to determine the most appropriate volume of water. This can be done by processing some test samples of spiking water (preferably similar to the samples) and determining how long the process takes. Typically, a volume is chosen that takes no more than $3 \mathrm{~h}$ to pass through the SPE cartridge, allowing time for sample preparation, elution and processing before analysis.

It is useful to validate methods by spiking known amounts of the cyanotoxin of interest into water samples. Spiking should not be performed with high-purity water (e.g., Milli-Q) as this may lead to poor recoveries, and as this is in no way representative of the samples being processed. Using the typical raw or tap water to be tested is best (if tap water is chlorinated, using a chlorine-quenching agent, i.e., sodium thiosulphate or ascorbic acid) as this will provide a good indication of expected performance.

\subsubsection{Enzyme-Linked Immunosorbent Assay (ELISA)}

Immunoassays are based on the binding interaction between a highly specific antibody and the analytes of interest. The most common of these assays is the ELISA kit using antibodies raised to specific cyanotoxins. The toxins are detected by the modification in the colour reaction with the intensity of the colour being inversely related to the amount of toxin.

ELISAs can offer rapid results with a relatively low investment in capital equipment. As these assays do not identify specific cyanotoxin variants of a toxin class and give an indication of total toxin concentration - total 


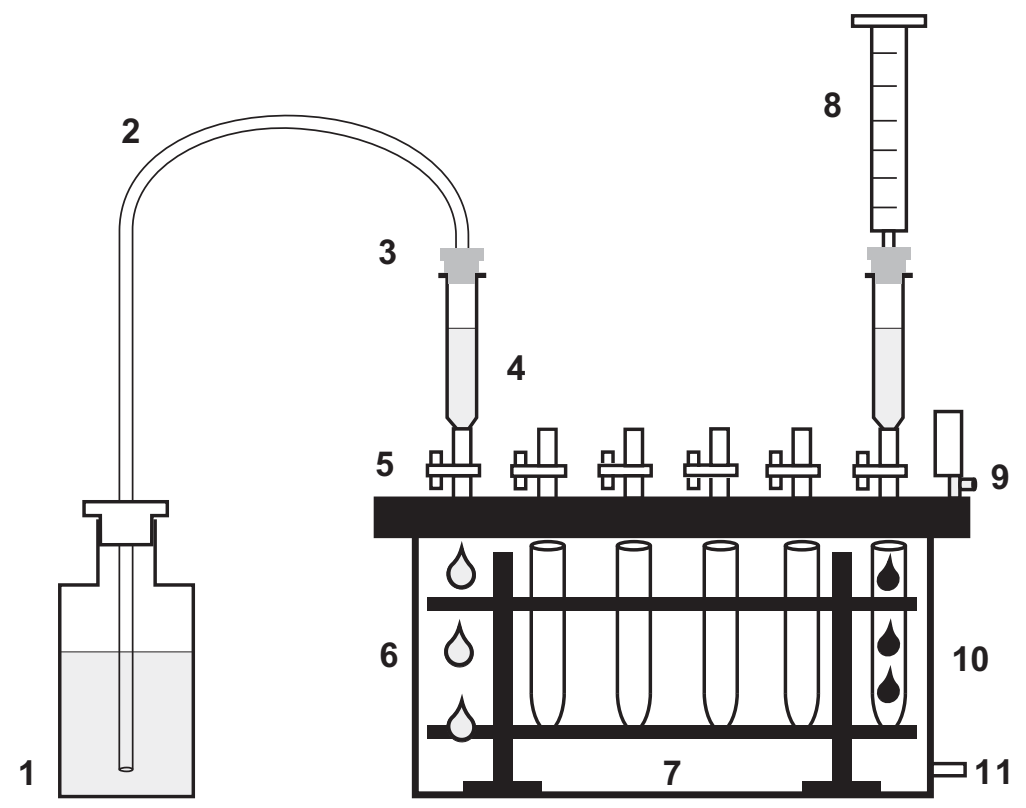

Figure 14.2 Setup for solid-phase extraction (SPE) for concentrating trace amounts of cyanotoxins dissolved in water. I. Filtered water sample in stoppered glass bottle; 2 . PTFE tubing carrying water under vacuum; 3. PTFE tubing; 4. SPE cartridge with sorbent; 5. PTFE stopcocks used to stop and start flow; 6 . water flowing to waste while cyanotoxins are adsorbed on the cartridge; 7. vacuum manifold system with removable rack; 8: reservoir used to introduce solvents for conditioning and eluting the cartridge (syringe); 9. pressure gauge with needle valve; 10 . concentrated sample eluted into a sample collection tube or vial; II. vacuum line connection.

microcystins, for example - they are often used as a screening method. It is recommended to confirm toxin content and to routinely check for false negatives using instrumental methods (HPLC, LC/MS; Gaget et al., 2017). Where such methods are not available, periodic shipping of a few selected samples to a support laboratory elsewhere may be an option.

ELISA kits are very popular for a rapid, straightforward detection of most classes of cyanotoxins, although an individual kit is required for each class of cyanotoxin and even different kits may be necessary to cover the variants within one class. The kit-based formats provide a straightforward guidance on how to perform, calibrate and interpret the results. Multiple samples can be evaluated at one time, and results can typically be reported in less than a day. As with all biochemical test kits, care has to be taken with storage, since ambient or elevated temperature during prolonged transportation can reduce their reliability. The 96-well plate format allows samples to be read and quantified in a plate reader, facilitating the analysis of many samples and the calibration in a short space of time. 
Kits often come with a removable strip format so that not all wells need to be used at the time of analysis thus increasing the cost-effectiveness of the assay. If only a few samples are to be assayed, it is advisable to confirm the format before making a purchase.

ELISA kits with sensitivity in the range of the WHO lifetime cyanotoxin guideline values are commercially available for almost all classes of cyanotoxins (see below). However, it is important to remember that cell-bound toxins need to be extracted prior to performing the ELISA. Also, care has to be taken to quench oxidants used in water treatment (chlorine or chlorine dioxide; see above) and to ensure the $\mathrm{pH}$ of the sample is appropriate for the specifications of the assay. Filtration or centrifugation may be required to remove particulates, and dilution may prove necessary to ensure that the quantification is in the approved range given in the instructions. Where the cost of these kits is a problem and access to producing antibodies is available, an option may be to produce antibodies in-house or to have this provided through co-operation with a an external institution (university, company, etc.), as demonstrated in the case study described in Box 15.1 in Chapter 15.

\subsubsection{High-performance liquid chromatography (HPLC)}

HPLC has become well established for the routine analysis of environmental pollutants. These systems consist of a solid-phase chromatography column through which analytes dissolved in liquid solvents are pumped and separated due to differences in the interaction of individual analytes with the solid phase. The flow then passes through a detector, for example, UV absorbance or fluorescence detectors, with the absorption proportional to the amount of analyte, with data collected on a computer. Most systems now include an autosampler to allow a set of samples to be loaded and automatically analysed. The number of samples that can be analysed in a given space of time depends primarily on the duration of a single sample run. For example, the run time for microcystins with a conventional HPLC is around $1 \mathrm{~h}$ per sample. Analyses with fewer target compounds, that is, less structural variants such as cylindrospermopsin or anatoxin-a, generally require shorter run times and hence allow a higher sample throughput. The separation of the analytes can be achieved by isocratic elution; this is when the solvent composition remains the same throughout the analysis. Isocratic elution is suitable for analyses that target only a few analytes and with a limited matrix interference, that is, with relatively low amounts of other, nontarget compounds. To allow for better separation of target analytes, gradient elution is commonly applied, where the proportions of the solvents change over the run time. This allows a wide range of analytes to be separated, such as multiple variants of microcystins. To ensure that analytes and contaminants are not carried over to the next sample, a washing step with $100 \%$ solvent is often included in the analytical run. 
The most common detector used on HPLC systems is the photodiode array (PDA), which will provide an adsorption spectrum $(200-600 \mathrm{~nm})$ for the compounds being analysed. This is useful for the analysis of cyanotoxins as many of them have characteristic UV absorption spectra (Figure 14.4 and 14.5), thus providing an indication even of cyanotoxins in the sample for which no standard reference material is available (see Box 14.2).

\section{BOX 14.2: REFERENCE MATERIAL FOR CALIBRATION}

According to IUPAC, reference material is defined as "a substance or mixture of substances, the composition of which is known within specified limits [...] to be used for the calibration of an apparatus". For cyanobacterial toxins to be used as reference material for establishing a calibration curve for the quantification of these cyanotoxins, two criteria need to be fulfilled:

I. Purity defines the share of an individual compound of the total material. Purity is generally expressed in gravimetric percent that should be at least $95 \%$ in reference material.

2. Amount is generally defined in gravimetric units, and ideally with the specified limits, that is, a range of amount that should be as narrow as possible.

In this sense, not all cyanotoxins that are commercially available are reference materials. Hence, these compounds cannot be used directly to establish calibration curves. In particular, the nominal amount in a vial may deviate considerably from the true amount. In consequence, this means that a calibration curve established with such a "standard" would introduce a systematic error to all subsequent analytical quantifications.

The true amount hence needs to be determined. This can be done either by weighing with a sufficiently precise and sensitive balance or by spectrophotometric analysis (ISO, 2005). For the latter, wavelength-specific extinction coefficients need to be available, which is the case for some but not all cyanotoxin variants. Extinction coefficients are specific for solvents and temperature; that is, a compound dissolved in water cannot be quantified by using an extinction coefficient established for the compound dissolved in methanol.

For cyanobacterial toxins sold as certified reference material, the purity as well as the amount is well defined, and its can be used directly as standard for calibration. 
The typical capital investment required for an HPLC is around $\$ 30,000$ USD with relatively modest costs for maintenance, including replacement UV lamps and columns.

Training of staff and adoption of a standard protocol is easily achievable, while interpretation of samples and cyanotoxin identification (especially unknowns from their spectra alone) requires more time to develop confidence. This applies equally to UPLC (ultra-performance liquid chromatography) discussed below.

\subsubsection{Ultra-performance liquid chromatography (UPLC)}

UPLC offers a considerable advantage over conventional HPLC as it allows very rapid separation of analytes (run times of around $10 \mathrm{~min}$ ) and a greatly reduced solvent usage, typically $0.3 \mathrm{~mL} / \mathrm{min}$ compared to $1 \mathrm{~mL} / \mathrm{min}$ for conventional HPLC systems. For example, these systems can achieve the separation of multiple microcystin variants in run times little over $10 \mathrm{~min}$, thus providing high throughput of samples, substantial saving and results on the same day for samples with short extraction times (e.g., bloom material and filter discs with cells). For samples requiring longer extraction (SPE of water samples or tissue samples), it can yield results within $24 \mathrm{~h}$.

UPLC systems are highly reliable with the response factor for microcystins in the UV detector changing little over time. The capital investment should typically be around \$50 000 USD for the complete system at relatively low levels of maintenance, with the main component that needs replacement being the UV lamp (it is useful to have a spare in stock).

\subsubsection{Liquid chromatography with mass spectrometry (LC-MS)}

The addition of a mass detector to chromatography systems makes a very powerful tool for the analysis of cyanotoxins. Mass spectra can provide an indication of the elemental composition and structure of an analyte along with determining the quantity of analytes for which reference materials are available with high sensitivity (see Box 14.2). A range of differing systems is available, and very careful consideration is required to determine which fulfils analytical requirements and is within the budget available. Different ion sources are available with positive electrospray ionisation (ESI) most commonly used in the analysis of cyanotoxins. The type of mass analyser (Caixach et al., 2017) also varies and can have a significant impact on cost and the data obtained; hence, it is essential that background evaluation is carried out to ensure the system suits the needs defined during planning (see section 14.1.1). In general, LC-MS will provide data relating to chromatographic retention times, the parent ion masses and fragmentation patterns 
for each compound as they are eluted. More complex LC-MS/MS systems combine a series of more than one mass detector (e.g., a triple quadrupole mass detector). As analyte ions pass through mass analysers, the former allow the selection of an analyte based on parent ion mass, while the latter allow the selective detection of fragment ions. This makes LC-MS/MS a highly specific analytical technique.

Robust protocols are required for LC-MS/MS as the signal from the MS can be either enhanced or suppressed by matrix interference (salts, organics, etc.). Furthermore, the response (i.e., signal strength relative to analyte amount) can drift over a relatively short time, necessitating a regular and frequent calibration. A routine maintenance protocol is advisable with the interval for cone cleaning determined for different sample matrixes; for example, in studies for the analysis of mussel tissue, cone cleaning was required after 40 samples (Waack, 2017). This interval was determined by spiking an extracted sample and then carrying out repeated, identical sample injections and determining after how many samples the reliability of the detection and quantification diminished.

While LC-MS provides very powerful sensitivity and detection capabilities, the more advanced systems (LC-MS/MS) require a capital investment of around \$500 000 USD and an annual running cost of \$20-40 000 . Furthermore, a high level of staff training is required to use, interpret and maintain these systems, but once established, they provide unrivalled analytical capabilities. It is advisable, where possible, to see one or several systems in operation and have an opportunity to analyse specific samples from the area to be monitored prior to committing to this significant capital investment.

\subsubsection{Selecting an analytical system}

The lack of suitable analytical equipment is typically a barrier to monitoring cyanotoxins, and a strong case is often made for capital investment. The influence of current scientific publications frequently draws attention to the significant capabilities of very advanced instrumentation. However, while these systems provide impressive capability, a robust evaluation of the analytical requirement, running costs and infrastructure should be made to inform purchasing decisions. Checklist 14.2 provides some key points to discuss both in-house and with those who have recently invested in cyanotoxin analysis before making decisions. In particular, it is advantageous to develop a regional network, sharing expertise and resources, for example, through a regional centre of competency. This may lead to a decision to use simpler techniques such as ELISA while validating the results periodically by having a small set of samples analysed with advanced techniques elsewhere. Where training is required, it is often more efficient to invite an expert to provide an in-house workshop as this ensures analyses 
are operational and staff develops confidence using the in-house system. (Note: small grants are often available for this, e.g., through international exchanges and workshop funding.) A further benefit of this approach is continued support from experienced international collaborators ensuring ongoing development of monitoring programmes. Support provided by the system's vendor generally is charged for. This should be considered in the budget for investment and running costs.

\section{CHECKLIST I4.2 EVALUATING INSTRUMENTAL ANALYTICAL REQUIREMENTS AND SUITABILITY}

- What information is needed? Which class of toxins will be the main focus? Is the main target monitoring compliance of cyanotoxin guideline levels?

- Check the cost of consumables, for example, vials, columns, SPE cartridges and solvents in relation to the number of samples expected over time. In many countries, solvents and even high-purity water can be prohibitively expensive (the benefits of ultra-performance liquid chromatography (UPLC) are low flow rates and short runtimes requiring little solvent).

- What are the costs of waste solvent disposal required by environmental legislation?

- Is the infrastructure appropriate? This includes a stable power supply as fluctuating or intermittent power can rapidly destroy equipment. If not, what are the costs of installing effective power surge protection such as uninterruptible power supply (UPS) systems?

- Can room temperature be kept within the range needed by the instruments and analyses (results can be affected by high or fluctuating temperature, so air conditioning is often required)?

- Do all purchases include installation and initial training, ensuring that there are available engineers in the area?

- What is the cost of a service contract, and is it essential?

- For planning to purchase a LC/MS (it requires a nitrogen generator and cannot run efficiently on regular laboratory gas cylinders), ensure that the contract includes either annual service - that is, the cost of service engineers visits - or, if you have technical expertise to carry out the service, the purchase of a service kit.

- Talk to users of different instrument manufacturers regarding their experience of service and support especially in your location.

- Consider the benefits of partnering with others rather than buying own equipment. 


\section{I4.3 QUANTIFICATION OF MICROCYSTINS AND NODULARINS}

Of all the cyanotoxins, most experience exists with the methodology for the extraction and detection of microcystins. Furthermore, due to its chemical similarity, many of the methods for microcystins will also readily detect nodularin (Lawton et al., 1994b); hence, it will be included in this section. In general, the term "microcystin" will be taken to refer to both these related classes of toxins unless the differentiation is required.

Methods range in complexity and sophistication, spanning the wellestablished "tried and tested" approaches through to preliminary research findings on novel detection strategies. While many of these novel methods offer exciting opportunities for the future, this chapter focuses on a few of the most relevant approaches for establishing routine methods suitable for the more widely available resources and common requirements.

\subsection{Extraction methods for microcystins and nodularins}

\subsection{I.I Cyanobacterial cells}

All cell/bloom samples will require extraction as these toxins tend to be retained inside healthy cells. Many extraction protocols for microcystins have been described (e.g., various solvent combinations, cycles of freeze/ thawing, sonication, freeze drying, including combined methods). Among these solvent combinations, aqueous methanol (typically 50-80\%; (Barco et al., 2005)) has proven to be very effective for extracting microcystins in face of their wide range of polarities. This solvent can be used for extracting cell pellets once a sample has been centrifuged (and the supernatant discarded or assayed for extracellular microcystin) as well as for extracting cells concentrated on filters. Depending on the volume of cells, around $90 \%$ recovery of microcystins (Barco et al., 2005) can be achieved with the first extraction. Often this is sufficient, as this has to be balanced against the further time required for processing a second extraction, as this will typically yield less than $10 \%$ of the total microcystin; also if the two extractions are combined, this reduces the detection limit due to the additional volume of solvent used in the second extraction. Extraction time of around $1 \mathrm{~h}$ is sufficient for good recovery. With the increased availability of dispersive extractor systems (automated vortexers that shake samples vigorously at defined speeds and timed duration), however, extraction can be achieved in just a few minutes and with high reproducibility. Where samples are extracted in centrifuge tubes (typically 1.5-mL microfuge), these can be spun and the supernatant then directly analysed using instrumental methods. 
When designing an extraction protocol, it is good to keep it as simple as possible as this will limit error and also potential workplace exposure to microcystins: for example, freeze drying is sometimes reported as a step during sample preparation if a specific dry weight of cells is to be determined, but this can produce powders that are difficult to contain and prone to static charge. Other methods also reported the use of a sonicator probe which may cause cross-contamination, but also produce aerosols.

The use of organic solvents (e.g., methanol) is not compatible with biochemical assays such as ELISA and enzyme inhibition tests. Some ELISA kit manufacturers provide a cell lysis kit, while other analysts have advocated aqueous extraction or dilution to limit the concentration of solvent: for example, a 1 in 10 dilution of a $50 \%$ aqueous methanol extract may be tolerated but should be checked with controls for the specific kit used. Since microcystins demonstrate high temperature stability, a brief exposure $(5 \mathrm{~min})$ of a small sample (e.g., $1 \mathrm{~mL})$ to about $80^{\circ} \mathrm{C}$ in a water bath followed by centrifugation $(13000 \times \mathrm{g}$; microfuge) can result in simple solventfree extraction (Metcalf \& Codd, 2000). Extracts can then be diluted in water or buffer as required.

Similarly, high organic solvent content in extracts to be analysed by chromatographic systems needs to be tested for compatibility, in particular when gradient elution is applied that generally starts with hydrophilic conditions.

\subsection{I.2 Water samples}

Some very sensitive methods (e.g., LC-MS/MS) may be able to detect microcystins at environmental concentrations. However, even then it may be desirable to carry out solid phase extraction (SPE) to limit matrix effects.

The most commonly used SPE material is end-capped C18 cartridges, which have demonstrated high recovery and reliability. Some users prefer newer resins (e.g., polymeric phases), which are good where MS is the detector of choice; however, the high recovery of polar compounds by these cartridges can interfere with the more polar microcystins (e.g., microcystin$\mathrm{RR}$ ) if detection is with photodiode array (PDA). Several published methods provide a good detail on establishing SPE extraction of microcystins (Lawton et al., 1994b; Triantis et al., 2017c).

Some researchers have developed online sample concentration for fully automated extraction and analysis of microcystins. This is typically an advanced option including LC/MS(MS) and a quite specialised approach; however, it may be desirable particularly for laboratories that need a high throughput, such as those of public authorities monitoring compliance to regulations or of drinking-water suppliers.

Recoveries are best if sample handling is limited, processing time is kept to a minimum and samples are analysed immediately or stored at $-20^{\circ} \mathrm{C}$ when this is not possible. There is some evidence that samples may change 
when stored for longer periods of time even at $-20^{\circ} \mathrm{C}$, but further studies are required to clarify the extent of this problem. If samples are stored, they should be vortexed if a subsample is to be removed after storage.

\subsubsection{Tissue samples}

It is becoming increasingly important to evaluate microcystins in more complex matrixes such as animals that have become intoxicated, fish and aquaculture products that may be contaminated or even plant materials. Much work is still required to fully understand the efficiency of different extraction and toxin recovery protocols. This is particularly challenging for microcystins and nodularins as they are known to bind to proteins; furthermore, microcystins, in particular, can bind covalently to certain protein phosphatases in living cells. Further, the recovery of standards spiked to the material to be tested will only represent unbound toxin recovery efficiency.

While a range of processing strategies with varying degrees of complexity have been used, all of these strategies need to be tested and tailored to the specific requirements of the material to be studied. Simple blending of fresh tissue (mussels) followed by a single aqueous methanolic ( $80 \%$ methanol) extraction was found to give good recoveries in the range of $61-97 \%$ for 11 microcystins and nodularin (Turner et al., 2018). Very poor recovery was observed for hydrophobic microcystins when either the samples were acidified or water alone was used. The solvent extracts can be directly analysed by instrumental systems. In contrast, for biochemical tests (ELISA or protein phosphatase inhibition), samples will need to be dried to remove the solvent or sufficiently diluted with water or buffer.

Due to the difficulties in detecting bound microcystin, a method was developed which is designed to cleave part of the microcystin at the first double bond of the ADDA moiety liberating 2-methyl-3-methoxy-4-phenylbutyric acid (MMPB; see Figure 14.3). The assumption behind this approach is that one molecule of MMPB is liberated for each molecule of microcystin, hence predicting the total microcystin content. An oxidation step is used to liberate the MMPB fragment from the parent microcystin, which is assumed to be simpler than digesting the microcystin bound to protein. While this

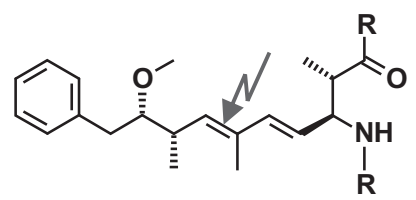

Figure 14.3 ADDA moiety of microcystins and nodularins with an indication of the site of MMPB cleavage. For the full structure, see section 2.I. 
method has been used in a range of studies, it is very difficult to determine the degree of sample recovery as spiking will only represent free toxin. Most reported studies currently use MS detection of MMPB $(\mathrm{m} / \mathrm{z} 208)$; however, this mass is not unique to this oxidation product (ChemSpider shows $>6300$ compound with this or very similar mass). Others have augmented the method to search for a product ion at 131, which again may not provide confident detection. However, Foss and Aubel (2015) have successfully used the MMPB method in comparison with the ADDA-ELISA, indicating good agreement.

In summary, the detection of microcystins and nodularins in tissue is important for assessing their possible role in animal poisoning or occurrence in food (fish, shellfish, vegetables, etc.), and while no current method will recover the total amount of microcystins, aqueous methanol extraction will give a good indication of whether microcystin is present.

\subsubsection{Quantification of microcystins and nodularins by biochemical methods}

\subsubsection{Quantification by protein phosphatase inhibition assay}

Microcystins and nodularins are known to be potent inhibitors of protein phosphatases PP1 and PP2A. This activity is central to their toxicity, and hence, detection of inhibition also indicates the potential biological activity of a sample. The assay can be performed relatively easily where the facilities are available for biochemical work. All the reagents and enzymes can be purchased for the colorimetric assay, which detects the enzymatic hydrolysis of the substrate ( $p$-nitrophenyl phosphate) that liberates the coloured product $p$-nitrophenol (detected at $405 \mathrm{~nm}$ ). The assay can be performed in a microtitre plate with the temperature, mixing and timing controlled by the plate reader and relatively straightforward protocol, typically resulting in good reproducibility.

Some challenges can arise if the sample inhibits the enzyme (depending on $\mathrm{pH}$, solvents or other contaminants) or if it contains background colour; however, this rarely occurs as the enzyme assay is highly sensitive, allowing a significant dilution of, for example, a cell extract. Detection limits as low as $0.0039 \mu \mathrm{g} / \mathrm{L}$ have been reported, which is well below the WHO guideline value (Sassolas et al., 2011). This assay is also available as a commercial kit, which has a quantification range between 0.25 and $2.5 \mu \mathrm{g} / \mathrm{L}$ and an analysis time of only $30 \mathrm{~min}$. The manufacturers also provide a tube format that could be used in the field and eliminate the need for investment in a plate reader, although users repeatedly analysing multiple samples will benefit from the multiwell plate format as this can be automatically analysed and is more practical for multiple samples and calibration points. 


\subsubsection{Immunoassays for microcystin and nodularin detection}

The ADDA-based ELISA is particularly popular as it has been designed to detect the ADDA moiety, which is both very specific to these toxins and present in all variants, regardless of other chemical diversity. Sensitivity is reported as around $0.1 \mu \mathrm{g} / \mathrm{L}$ with the assay time of $2.5 \mathrm{~h}$. There are a range of ELISA kits (usually with antibodies raised to microcystin-LR), and it is worthwhile checking which would be most appropriate for use in a specific situation. Considerations may be cost, format, location of suppliers and experience of other users in the vicinity. ELISA has been used for a range of samples demonstrating a good cross-reactivity for a number of variants and different sample matrices (Heussner et al., 2014); however, for tissue samples, sample processing needs a careful consideration as some studies have reported false positives and concentrations which are greatly in excess of the levels detected by LC-MS/MS (Brown et al., 2018).

\subsubsection{Instrumental analytical methods for microcystins and nodularins}

While a range of analytical approaches has been explored over the past 30 years, the central method of choice revolves around liquid chromatography (LC). Microcystins and nodularins can be separated very readily on C18 reverse-phase columns, although some closely eluting variants (e.g., microcystin-LR and desmethyl-microcystin-LR) require a careful column selection. Different methods of detection have also been evaluated, with a general consensus on UV detection and/or mass spectrometry, including MS/MS.

\subsubsection{Analysis of microcystins and nodularins by HPLC-PDA}

High-performance liquid chromatography with photodiode array (HPLCPDA) provides an accessible, robust method for the detection and quantification of all microcystins by virtue of their distinct UV absorption spectra (Lawton et al., 1994b). Even in the absence of standards for every microcystin, confident quantification of total microcystins can be achieved. Most microcystins have very similar absorption spectra (although the overall characteristics between 200 and $300 \mathrm{~nm}$ can vary with concentration) with a maximum at $238 \mathrm{~nm}$ from the conjugated double bond in the ADDA moiety (Figure 14.4). The exception to this are microcystins that contain the variable amino acid tryptophan (e.g., microcystin-LW), which have an absorption maximum at $223 \mathrm{~nm}$, and those that contain the variable amino acid tyrosine (e.g., microcystin-YR), which have an absorption maximum at $231 \mathrm{~nm}$ (Figure 14.4). A simple approach is to use microcystin-LR calibration for total microcystin quantification, assuming a similar molar 
(a)

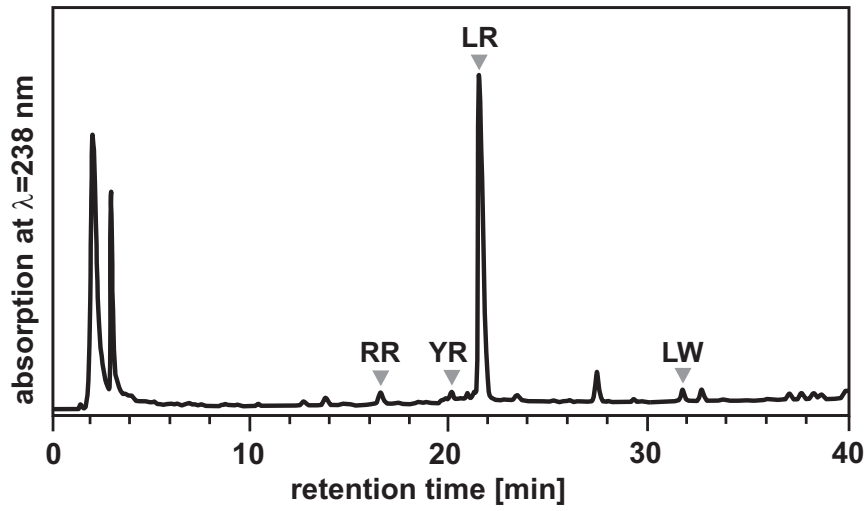

(b)

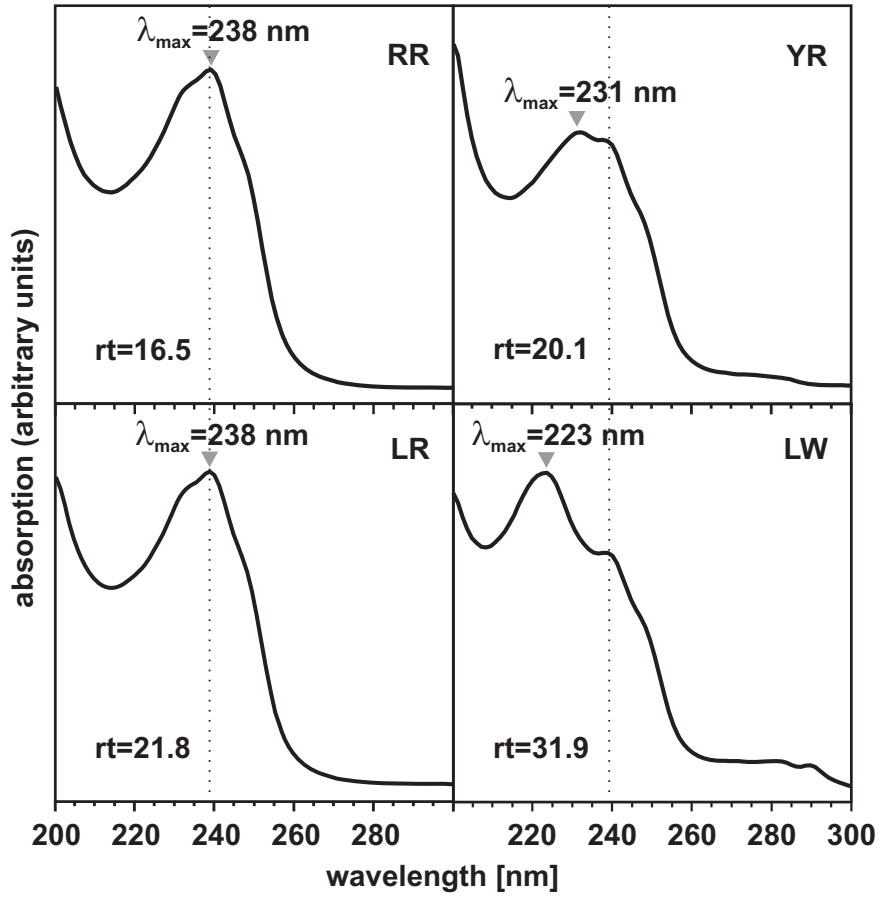

Figure 14.4 HPLC-PDA chromatogram of a bloom sample dominated by Microcystis sp. (a) and UV-absorption spectra of selected microcystin peaks (b). The individual variants are indicated by the standard two-letter code. $\mathrm{rt}$ : chromatographic retention time. The dotted line in the spectral plots indicates the wavelength $\lambda=238 \mathrm{~nm}$; all microcystins show an absorption band at this wavelength that results in a shoulder in the spectra of variants containing tyrosine ( $(Y)$ and tryptophan (W). A second absorption band at $\lambda=246 \mathrm{~nm}$ can be seen as shoulder in spectra of all microcystins. Both absorption bands are related to the conjugated double bond of the conserved ADDA moiety. For analytical details, see Welker et al. (2003). 
absorption coefficient at $238 \mathrm{~nm}$, that is, a similar response in PDA detection. An advantage of HPLC-PDA analysis is the fact that microcystin variants for which no reference material is available can be recognised based on a peak's absorption spectrum. Verification can be achieved by collecting the eluting peak and performing an offline analysis, for example, by MALDITOF MS (Welker et al., 2002b). Beyond this, it is preferable to set up the method with a range of microcystin variants of differing polarities, spanning from early to late retention, to provide confidence that a wide range of microcystins can be detected should they occur in samples.

The typical analytical set-up will be a gradient separation using highpurity water plus trifluoroacetic acid (TFA; $0.05 \%$ ) and acetonitrile with TFA $(0.05 \%)$. A gradient from $30 \%$ to $70 \%$ acetonitrile is usually required to separate all microcystins, and a rapid wash to $100 \%$ will eliminate carryover between runs.

\subsubsection{Analysis of microcystins and nodularins by LC-MS(MS)}

Both LC-MS and LC-MS/MS are powerful instruments for the analysis of microcystins. For developing a new method for microcystin analysis by LC-MS/MS, the Handbook of Cyanobacterial Monitoring and Cyanotoxin Analysis (Meriluoto et al., 2017) provides good guidance and a number of standard operating procedures (SOPs). Different approaches are possible, including the detection only of microcystins for which standards are available, using selected reaction monitoring (SRM), which is very sensitive and accurate (Turner et al. 2018). The drawback of this approach, however, is that a significant proportion of the microcystins in a sample could go unreported - those variants for which no calibration has been established based on standards. For example, USEPA Method 544 (Shoemaker et al., 2015) is limited to six microcystins, while other published methods have extended this to over 10. Birbeck et al. (2019) reported $40 \%$ of samples had more than $20 \%$ of their total microcystin variants not detected by the USEPA Method 544 and a number of these variants were the dominant microcystins. It is therefore advised to consider the taxonomic composition of the sample that allows a tentative prediction of the structural variants to be present. A way forward for routine monitoring is a detailed initial analysis to identify the spectrum of microcystins, and as long as bloom composition stays stable, such SRM can be a robust and sensitive approach, provided periodic checks are carried out to confirm that the overall microcystin profile is still covered by the standards used.

If microcystin variants are to be quantified for which no purified quantitative standards are available, estimates on the basis of their retention characteristics, mass and fragmentation pattern can serve for an initial assessment. However, as detector response intensities vary substantially between individual variants, a quantitation can be at best tentative; for 
example, MC-RR has a several-fold higher response than MC-LR, probably due to a higher ionisation efficiency (Krause et al., 1999). A valuable approach is to add a PDA detector to the system along with the MS detection: this will greatly enhance confident detection and in particular quantification of microcystins for which no specific calibration could be established. Since the PDA is robust and quantification varies little over time, it provides an excellent confirmation and quantification.

\section{I4.4 QUANTIFICATION OF CYLINDROSPERMOPSINS}

Cylindrospermopsin (CYN), including its small number of variants, is highly polar due to its zwitterionic nature, and hence, is readily soluble in water. Unlike most of the other cyanotoxins, it is often found in significant concentrations outside the cell as well as within the cell (section 2.2). It appears to be relatively stable and to some extent resistant to a rapid biodegradation. Detection appears to be limited to either ELISA or chromatography (with photodiode array (PDA) and/or MS).

\subsection{Extraction of cylindrospermopsins}

\subsection{I.I Cyanobacterial cells}

Extrtaction of cylindrospermopsins from dried cells can be simply achieved in water (Welker et al., 2002a). A known amount of freeze-dried cells can be weighted into a microcentrifuge tube and extracted with $1 \mathrm{~mL}$ of water added by vortexing intermittently for $1 \mathrm{~h}$ or placing in a dispersive extractor for $2 \mathrm{~min}$ at a full speed. The sample should then be centrifuged $(13000 \times \mathrm{g})$, and the supernatant can be directly analysed by either ELISA or chromatography. With fresh cells, a similar protocol can be followed by first centrifuging the fresh sample and retaining the supernatant for analysis. The cell pellet can then be extracted in $50 \%$ aqueous methanol, although care has to be taken either to remove the methanol by drying the sample or to dilute it, since the methanol will interfere with both ELISA and peak shape in chromatography (Metcalf et al., 2002a).

\subsubsection{Water samples}

Low concentrations of cylindrospermopsins in water will require sample concentration by solid phase extraction (SPE; Triantis et al., 2017a). Due to the polarity of the molecule, it is poorly retained by C18 and other solid media typically used for water analysis. Good recoveries can be achieved by the specialised cartridges such as graphitised carbon or polymeric resins. The typical protocol requires the filtration of a water sample (the filter should be extracted for cell-bound cylindrospermopsins) and then passing 
the sample through the preconditioned cartridge. Recovery can be significantly affected by the loading speed so this should be carefully controlled and optimised for the protocol being used. Cylindrospermopsins are eluted from the cartridge with methanol. It is useful to spike some samples of the water to be analysed as well as tap water (quenching any oxidant such as chlorine) to both become familiarised with the process and to define a standard operating procedure $(\mathrm{SOP})$ within the laboratory.

\subsection{I.3 Tissue and urine samples}

Most accounts of studies investigating the localisation of cylindrospermopsins in experimental animals have indicated that unaltered cylindrospermopsins can be excreted in the urine (Norris et al., 2001); hence, methods to detect it in this matrix can be useful where human exposure is suspected. This has been successfully achieved through salt removal and SPE (carbograph or other hydrophobic analyte recovery solid-phase) clean-up and concentration (Foss \& Aubel, 2013). Similarly, cylindrospermopsin has been recovered from serum samples although in these samples the focus is on protein precipitation with solvent (methanol) prior to SPE.

Good recovery of cylindrospermopsin from tissue (e.g., fish, mussels and vegetables) has been shown in a limited number of studies (Prieto et al., 2018) using aqueous solvents (typically methanol, aqueous methanol or acetic acid), although these methods may require further testing to determine the optimum protocol. Depending on the matrix and concentrations, direct analysis without SPE may give satisfactory results.

\subsubsection{Quantification of cylindrospermopsins by ELISA}

Cylindrospermopsin is a protein synthesis inhibitor, and as such, biological assays can be relatively slow and nonspecific. Therefore, the favoured assay is the cylindrospermopsin-specific ELISA kit. Several ELISA kits are commercially available for cylindrospermopsin with detection limits well below $1 \mu \mathrm{g} / \mathrm{L}$, and these kits can be used directly on water samples. As the proportion of extracellular to cell-bound cylindrospermopsin can vary significantly, it is important to test for both the cell bound and free toxin. Use of kits will require relatively modest investment of a plate reader and the expense of the purchase of the kits. Full instructions for performing the assay, calibration and validation are provided with each kit. When establishing the use of ELISA, matching results with HPLC for selected samples and matrices will be valuable for determining the level of confidence as false positives have been shown with low-positive concentrations (Metcalf et al., 2017). 


\subsubsection{Instrumental analytical methods for cylindrospermopsins}

As cylindrospermopsin is a very polar analyte, it is poorly retained on many C18 columns. Some columns have become available, which are better suited to the retention and separation of cylindrospermopsin and its variants (e.g., polar retention C18, graphitised carbon); therefore, it is advisable to select a column that is specifically designed for highly polar compounds (de la Cruz et al., 2013).

\subsubsection{Analysis of cylindrospermopsins by HPLC-PDA}

Cylindrospermopsins have a characteristic UV spectrum with an absorption maximum at $262 \mathrm{~nm}$ (Figure 14.5). This spectrum can be used to distinguish cylindrospermopsin from other peaks on the chromatogram in a way similar to that for microcystins. Chromatography is either carried out isocratically

(a)
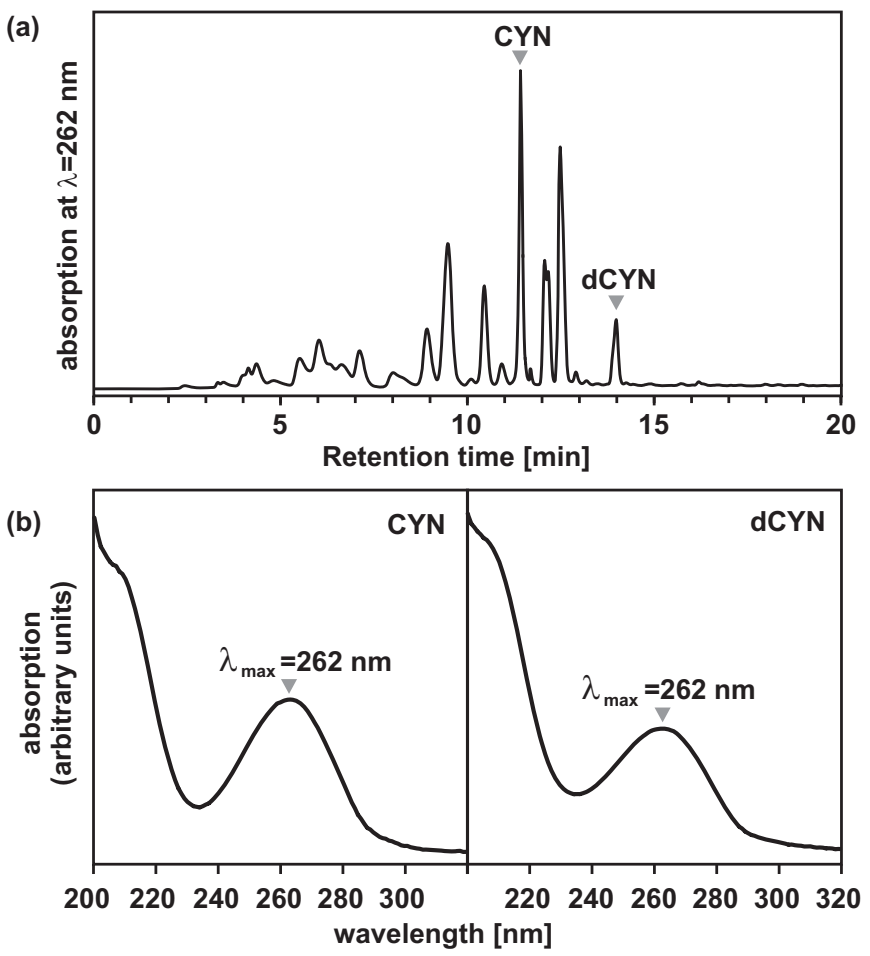

Figure 14.5 HPLC-PDA chromatogram of a bloom sample dominated by Cylindrospermopsis sp. (a) and absorption spectra of the two cylindrospermopsin variants (b), cylindrospermopsin (CYN) and 7-deoxy-cylindrospermosin (dCYN), showing an absorption maximum at $\lambda=262 \mathrm{~nm}$. For analytical details, see Welker et al. (2002a). 
( $5 \%$ organic solvent, methanol or acetonitrile with $95 \%$ water) or using a slow gradient (e.g., from $0 \%$ to $10 \%$ methanol) with $100 \%$ solvent wash, which limits carryover of other contaminant peaks especially from crude extracts (e.g., cells, tissue). Extracts can be analysed directly, while water samples will require SPE-concentration. Where samples are in a high proportion of methanol, this can affect chromatography. It is therefore advisable to either dry and resuspend the extract in water or dilute in water (e.g., 1 in 10, if concentrations in relation to the detection limit are sufficiently high). Using a guard column can eliminate the negative impact of methanol on the chromatography.

Hydrophilic interaction liquid chromatography (HILIC) columns have also been evaluated for the analysis of cylindrospermopsin separation due to their suitability for highly polar compounds. These columns tend to be less robust and may not separate cylindrospermopsin as well as the high-polarity C18 phases; however, they are continually improving and increasingly becoming the column of choice for the polar cyanotoxins (cylindrospermopsin, anatoxin-a and saxitoxin), allowing the analysis of these cyanotoxins together in one run (Haddad et al., 2019).

\subsubsection{Analysis of cylindrospermopsins by LC-MS(MS)}

Cylindrospermopsin is readily detected by mass spectrometry using chromatography conditions similar to those for HPLC-PDA. Electrospray in positive ionisation mode yields the parent ion with $\mathrm{m} / \mathrm{z} 416$ and product ions with $m / z$ 194, 176, 336 and 274. Selected reaction monitoring (SRM) can provide highly specific detection (Triantis et al., 2017a). Detection of cylindrospermopsin in drinking-water by this method with prior SPE concentration gave good recoveries at $0.01 \mu \mathrm{g} / \mathrm{L}(67 \%)$ and $0.1 \mu \mathrm{g} / \mathrm{L}(85 \%)$. Since there are only few other cylindrospermopsin variants, it is much less likely that MS detection will miss structural variants as in the case of microcystins. US EPA Method 545 based on LC-MS/MS has a minimum reporting level of 0.06 $\mu \mathrm{g} / \mathrm{L}$ for finished drinking-water (US EPA, 2015); for ambient freshwaters, Shoemaker and Dietrich (2017) give a minimum reporting level of $0.23 \mu \mathrm{g} / \mathrm{L}$. The analysis of cylindrospermopsin along with other more polar cyanotoxins (deoxycylindrospermopsin, anatoxin-a and saxitoxin) has been successfully achieved using HILIC-MS, demonstrating a robust detection of these toxins in cultured samples and bloom extracts (Dell'Aversano et al., 2004).

\section{I4.5 QUANTIFICATION OF ANATOXINS}

Anatoxin-a and its analogues, homoanatoxin-a and dihydro-anatoxin-a, can readily be detected by both HPLC and LC-MS/MS, and while GC/MS can also be used, this is not commonly done. As with many other cyanotoxins, ELISA kits are available for rapid detection (less than $2 \mathrm{~h}$ ). 


\subsection{Extraction of anatoxins}

Anatoxin-a can often be found in benthic cyanobacteria growing on surfaces of, for example rocks, riverbeds and submerged macrophytes. Anatoxins produced by these cyanobacteria has been implicated in animal fatalities. Addressing the occurrence of benthic cyanobacteria requires different sampling strategies than for pelagic cyanobacteria (Chapter 12).

\subsection{I.I Cyanobacterial cells}

Anatoxin-a has been successfully extracted efficiently from cyanobacterial cells using acidified solvents, either just water or methanol or a mixture of both (e.g., 50\% acidified aqueous methanol). This provides good recoveries and a relatively clean sample, although if microcystins are also going to be analysed from the same extract, it is advisable to omit the acid as it will adversely affect the recovery of more hydrophobic microcystins. Where samples are used for biological tests that would be sensitive to acid and/or organic solvents, extraction by multiple freeze/thawing cycles in water is preferable and has been successfully used.

\subsection{I.2 Water samples}

While anatoxins are largely cell-bound, it has also been observed to occur dissolved in water (Wood et al., 2018). Anatoxins are increasingly included in drinking-water monitoring during bloom episodes. ELISA kits can be used to determine toxin concentration without further extraction, merely after filtering the sample for cell removal. For instrumental analytical methods, particularly HPLC, concentration by SPE is required, and both C18 and graphitised carbon have been successfully used (Triantis et al., 2017b). Where mass spectrometry is going to be used for detection, a stable isotope-labelled phenylalanine- $d 5$ can be used as an internal standard to determine the recovery efficiency.

\subsection{I.3 Tissue samples}

Very few studies have determined the recovery of anatoxins from tissue samples, generally applying methods similar to those applied for analysis of anatoxins in cyanobacterial cells. Using acidified aqueous methanol can help provide a cleaner extract since both the solvent and acid will precipitate proteins. Further sample clean-up and concentration can be achieved by an additional SPE step.

\subsubsection{Quantification of anatoxins by ELISA}

ELISA kits are commercially available for the detection and quantification of anatoxin-a and homoanatoxin-a with quantification reported in the range 
of $0.15-5.0 \mu \mathrm{g} / \mathrm{L}$. Typically, the assay takes around $2 \mathrm{~h}$ and is suitable for extracts of cells and toxins dissolved in water. These kits have been used to determine anatoxin-a concentrations in field samples (John et al., 2019) and throughout the water treatment train (Almuhtaram et al., 2018). As always, when applying such kits to finished drinking-water, care should be taken to quench oxidants when sampling.

\subsubsection{Instrumental analytical methods for anatoxins}

The most commonly used analytical system for the detection, identification and quantification of anatoxin-a is HPLC-PDA or LC/MS(MS). The advantage of ultra-performance liquid chromatography (UPLC) columns and systems is that they allow short retention times, providing a rapid analysis. One of the main challenges for the analysis of anatoxin-a is the ubiquitous co-occurrence of phenylalanine, which has a very similar retention time and mass. It is important to ensure that the selected chromatography column and elution profile can separate the two compounds (see Box 5.3 for an example of this misinterpretation of analytical results).

\subsubsection{Analysis of anatoxins by HPLC-PDA}

Chromatography for anatoxin analysis is the same for HPLC-PDA and the LC-MS(MS), for example, a gradient mobile phase consisting of water/ acetonitrile (both acidified with $0.1 \%$ formic acid) where the organic phase is increased from a low proportion of organic solvent (e.g., $2-5 \%$ to around $35 \%$ over $5 \mathrm{~min}$ (for UPLC)) at a flow rate between 0.3 and $0.4 \mathrm{~mL} / \mathrm{min}$. Samples can be separated on a suitable UPLC C18 column typically maintained at $40^{\circ} \mathrm{C}$ (Colas et al., 2020). For photodiode array (PDA) detection, scanning between 200 and $300 \mathrm{~nm}$ can be sufficient, with anatoxin-a showing a distinct absorption maximum at $227 \mathrm{~nm}$. Spiking of separate samples with both anatoxin-a and phenylalanine helps to ensure that both compounds are well separated and to establish a specific retention. A "similar retention time" is not sufficient to assign a peak to anatoxin-a as described in Box 5.3. Notably, dihydoanatoxin-a and dihydrohomoanatoxin-a do not show a distinct UV absorption spectrum due to the lack of the double-bond in the molecule, which makes it difficult to distinguish these variants from the background matrix by photometric detection without florescence derivatisation (James et al., 1998).

\subsubsection{Analysis of anatoxins by LC-MS(MS)}

The same chromatographic conditions are also appropriate for chromatographic separation prior to mass spectral detection via positive ESI. The parent ion $[\mathrm{M}+\mathrm{H}]^{+} 166.1$ is identical for anatoxin-a and phenylalanine, although, 
as described above, with the suitable column the two compounds can be distinctly separated. This has been achieved on both C18 and hydrophilic interaction liquid chromatography (HILIC) columns, however, not necessarily on all brands. For anatoxin-a dissolved in water, spiking with stable isotope-labelled phenylalanine- $d 5$ allows estimates on recovery during SPE. The labelled phenylalanine elutes at the same retention time as phenylalanine occurring in the sample, but can be accurately quantified due to its altered mass $(m / z 171)$. US EPA drinking and ambient water ATX method based on LC-MS/MS has minimum reporting levels below $0.1 \mu \mathrm{g} / \mathrm{L}$ (Shoemaker \& Dietrich, 2017). Parent ions of homoanatoxin-a and dihydroanatoxin-a are $[\mathrm{M}+\mathrm{H}]^{+} 180.1$ and $[\mathrm{M}+\mathrm{H}]^{+}$168.1, respectively (see section 2.3).

\section{I4.6 QUANTIFICATION OF SAXITOXINS}

The identification and quantification of saxitoxins is challenging although there is a lot to be learned from the analysis of this toxin class in marine harmful algal blooms (HABs). In shellfish, monitoring with a mouse bioassay developed in the 1930s was still the benchmark until the validation of an analytical method in 2005 (Box 14.4). At least 57 saxitoxin variants have been reported (Wiese et al., 2010), but not all of these variants have been found in cyanobacteria (section 2.4). Furthermore, accurate information on the prevalence of different variants has been hampered by the complexity of analysis. It is known that saxitoxins can transform into different analogues (Wiese et al., 2010); hence, care has to be taken to ensure the stability of samples and standard solutions. In general, acidic solutions (e.g., $\mathrm{HCl}$ ) are considered suitable (Alfonso et al., 1994).

\subsection{Extraction of saxitoxins}

Saxitoxins are highly polar, and extraction protocols tend to use acidic conditions. The extraction methods for saxitoxins extensively studied for marine shellfish are also suitable for freshwater saxitoxins. A protocol to extract STXs from a range of matrices is available from AOAC (AOAC, 2005b). Solid phase extraction (SPE) using graphitised carbon or HILIC resins, for example, can be used to concentrate STXs for achieving lower detection limits or for sample clean-up (Humpage et al., 2010; Testai et al., 2016).

\subsection{I.I Cyanobacterial cells}

Saxitoxins typically occur cell bound, but up to $40 \%$ of the total amount has also been found extracellularly. As for cylindrospermopsin, it is therefore important to include both fractions - toxin dissolved in water and cellbound toxin - in the determination of total toxin. Separation of fractions 
can be done either by filtration during sampling or soon afterwards in the laboratory by centrifugation or filtration. The cells preferably are extracted in acidified solvent, and the supernatant can be directly used for analysis.

\subsubsection{Water samples}

Saxitoxins in water need to be concentrated, which can be achieved by SPE (Imhof \& Schmidt, 2017) with cartridges suitable for very polar compounds (e.g., porous graphitised carbon). It is recommended to evaluate the suitability of the selected cartridges and protocol by determining recovery using spiked (dechlorinated) tap water or filtrated lake water.

\subsubsection{Tissue samples}

Extraction of saxitoxins has been well described for marine shellfish samples. It involves homogenising tissue in a blender with the addition of acidified solvent, typically $1 \%$ acetic acid solution (AOAC, 2005b; 2011; Van De Riet et al., 2011). Prior to testing in a biological system, for example, ELISA, the $\mathrm{pH}$ will need to be adjusted to around 7.

\subsubsection{Quantification of saxitoxins by biochemical methods}

Several biochemical assays have been developed in the past but with the exception of ELISA, most have not been widely adopted, mainly because of their complexity and specialist expertise required to perform them.

\subsubsection{Quantification of saxitoxins by ELISA}

There are a number of (in 2019 at least six) manufacturers of different ELISA kits for saxitoxins. Most have been configured to detect saxitoxin, achieving good correlation with analytical results; however, there are challenges with cross-reactivity with other saxitoxin variants. This is of particular concern for neo-saxitoxin and gonyautoxin (GTX) variants since these variants represent as high a risk to health as saxitoxin (Papageorgiou et al., 2005). Some innovative methods are available which add an additional sample preparation step (e.g., incubation in the presence of $L$-cysteine) to transform most of the GTX variants to detectable saxitoxin or neo-saxitoxin (McCall et al., 2019). Some manufacturers produce an ELISA for saxitoxin and another kit for neo-saxitoxin. Recently, a multiplex ELISA has been demonstrated which detected nine saxitoxins in human plasma (Eangoor et al., 2019).

Careful selection of the most appropriate kit for screening purposes is important and should consider regional availability, cross-reactivity and the saxitoxin variants prevalent in the area of sampling (Harrison et al., 2016). As with all ELISA screening methods for cyanotoxins, it is wise to periodically 
confirm findings using an established instrumental analytical method. This may be achieved through collaboration with a centre of excellence rather than own investment in equipment for instrumental analytical methods and the corresponding expertise, as this can be considerable (see below).

\subsubsection{Instrumental analytical methods for saxitoxins}

The analysis of saxitoxins has been fraught with many difficulties as saxitoxins do not contain a chromophore (do not adsorb light) nor natural fluorescence; hence, typical HPLC detectors cannot be used to identify or quantify them. Further, they are very polar molecules that are not easily retained by reverse-phase chromatography (e.g., using C18 columns). Derivatisation to form a fluorescent analyte has proven valuable, with both precolumn and postcolumn (i.e., the saxitoxins are first chromatographically separated and then mixed with the derivatisation reagents before detection) methods developed and the precolumn method becoming an AOAC Official Method (AOAC, 2005b; 2011). While this method is validated for the analysis of paralytic shellfish poisoning in shellfish, it is also suitable for the analysis of saxitoxins from cyanobacteria in cells, water and tissues.

\subsubsection{Prechromatographic oxidation and liquid chromatography with fluorescence detection}

To overcome the difficulties of detecting saxitoxins, a preanalysis oxidation method was developed by Lawrence et al. (1995) allowing the saxitoxins to be analysed using a fluorescence detector (fluorescence excitation $340 \mathrm{~nm}$ and emission $395 \mathrm{~nm}$ ). Around the same time, Oshima (1995) proposed a postcolumn derivatisation method. The so-called Lawrence method with precolumn sample oxidation has now been adopted for regulatory monitoring purposes and is being used in many laboratories as part of routine monitoring programmes for saxitoxins in shellfish. The attention this method has received has ensured significant performance testing, including interlaboratory studies (Turner et al., 2019). This analysis requires a significant commitment to setting up and maintaining the method, including purchasing a wide range of standards. Where intermittent confirmatory analysis of ELISA results is required, it is beneficial to approach a laboratory which is already well established in this field rather than committing to the onerous task of developing this method in-house.

\subsubsection{Analysis of saxitoxins by LC-MSIMS}

Ultra-performance liquid chromatography (UPLC) with MS/MS provides a very powerful analytical tool for the detection, identification and quantification of saxitoxins at very low limits of quantification in the sub-ng/mL 
range. Several chromatographic approaches can be used, one being the more traditional C18 columns with a high proportion of water in the gradient elution. Alternatively, by using hydrophilic interaction liquid chromatography (HILIC), which is well suited to highly polar analytes, a rapid analysis has become possible with fast UPLC columns (e.g., 11 min compared to a previous $40 \mathrm{~min})$. Furthermore, the solvent-rich mobile phase used in HILIC can provide a significant advantage. One recent study demonstrated the separation, identification and quantification of 14 saxitoxins in less than $10 \mathrm{~min}$ (Turner et al., 2015).

Another promising approach to the detection of saxitoxins is the use of inline SPE coupled with C18 UPLC-MS/MS. This approach effectively combines sample extraction and concentration from a water sample which is then directly injected onto the analytical system. The full automation has many advantages in reducing staff time, handling errors and sample loss as well as giving a low limit of quantification (Imhof \& Schmidt, 2017).

\subsection{DETECTION AND QUANTIFICATION OF ANATOXIN-A(S)}

Work on anatoxin-a $(S)$ has been hampered by the limited availability of cultures which produce this cyanotoxin, which subsequently limits the availability of the purified toxin. This is further restricted by the difficulty in detecting anatoxin-a(S) in natural samples. As an organophosphate inhibitor, anatoxin-a $(S)$ can potentially be detected with a biochemical screening assay using an acetylcholine esterase inhibition assay. However, since organophosphate pesticides may be present in environmental samples, confirmation is required. Furthermore, in the absence of any authentic purified anatoxin-a(S) and confirmatory analytical methods, few reports of anatoxin-a(S) have been confirmed.

With greater availability and use of HILIC columns along with MS/MS (Dörr et al., 2010), it may be expected that gradually anatoxin-a(S) will become more widely detected, isolated and investigated. When planning sampling campaigns, it may be useful to give consideration to the possible presence of anatoxin-a(S), preferably in collaboration with expert groups able to screen samples with advanced multitoxin methods.

\section{I4.8 METHODS FOR SYNCHRONOUS DETECTION OF MULTIPLE TYPES OF CYANOTOXIN}

\subsection{Multiplex antibody systems}

Methods are likely to become available which allow the detection and quantification of multiple cyanotoxins in a single system (Eangoor et al., 2019). These systems are referred to as bioarray, microarray or multiplex systems. 
One such system using fluorescence detection of antibody binding signals has been found to be very sensitive, allowing the detection of microcystins, saxitoxins and cylindrospermopsin along with two of the marine shellfish toxins, okadaic acid (OA) and domoic acid (McNamee et al., 2014). Assay time was around $15 \mathrm{~min}$ per sample, providing results for all five biotoxins at once and in the sub- $\mu \mathrm{g} / \mathrm{L}$ range. While these systems are yet to become widely available, this type of screening is likely to become increasingly adopted in the near future with applications in screening of drinking-water quality and recreational waterbodies.

\subsubsection{Multi-cyanotoxin analytical methods}

An increasing number of instrumental methods which can analyse cyanotoxins in a single analytical chromatography run have been published (Dell'Aversano et al., 2004; Greer et al., 2016; Zervou et al., 2017). With the use of the optimal UPLC column and MS/MS detection, multitoxin methods are convenient where advanced analytical systems are routinely employed. Pekar et al. (2016) demonstrated the separation of anatoxin-a, cylindrospermopsin and microcystin variants, achieving the analysis of 22 cyanotoxins in both raw water and drinking-water Haddad et al. (2019) have added saxitoxin to the analysis, allowing the separation of four classes of cyanotoxin in a single analytical method.

\subsection{FUTURE DEVELOPMENTS}

With increasing legislation and pressure on water resources causing more demand to test for cyanobacterial toxins, rapid simple screening tests are increasingly likely to be required. These advances will most likely employ immunological, biosensors and related technologies to permit a rapid simple assessment of cyanobacterial and water samples after extracting cell-bound toxins. Immunological strip detection systems have been commercially developed (e.g., Kim et al., 2013; Weller, 2013), and such technologies are being adapted to furthering our understanding of cyanobacteria and their toxins in the environment.

Increasingly, cyanotoxin analytical methods will be required to analyse a wider complexity of novel materials that may require method development (e.g., in food; see section 5.3). In the case of cyanotoxins that do not covalently bind to proteins, simple extraction and clean-up methods with SPE should permit accurate analysis, although verification will still be required. Combined single-step SPE methods for sample preparation of, for example, cylindrospermopsins, anatoxin-a and saxitoxins should be developed to extract such cyanotoxins in an effort to reduce sample preparation for their subsequent measurement with, for example, mass spectrometry (Fayad et al., 2015). 
Although more specialised analytical methods such as mass spectrometry will continue to be required to verify cyanotoxins, future needs will be to develop methods for not yet identified bioactive compounds produced by cyanobacteria and to develop robust multitoxin analytical methods.

Further advances may come with the use of biosensors, such as with recombinant PP1 $\alpha$ showing an increased sensitivity for microcystin-LR (Catanante et al., 2015), 3D-graphene-based biosensors (Zhang et al., 2017) for the detection of microcystin-LR or DNA-based aptamer systems, either for the detection of Microcystis (Tong et al., 2015) or for the detection of microcystin (Li et al., 2016). Assay systems such as this show good promise and may be useful in future to provide quantitative and toxicological assessment of cyanobacterial toxins.

\section{I4.IO BIOASSAYS AND THEIR USE IN THE SURVEY OF TOXIC CYANOBACTERIA}

Assessments of potentially toxic environmental samples, including blooms of cyanobacteria, most commonly rely on chemical monitoring of individual chemicals, that is, the targeted analytical or bioanalytical identification and quantification of known toxins as outlined above. With respect to quality assurance/quality control (QA/QC) criteria and straightforward interpretation of the results, chemical monitoring is an approach generally applied in all regulatory settings, including water quality and safety. The obvious limitation of chemical monitoring is the fact that many analytical methods detect only those toxins that they target, which could often be only a single or a few structural variants, while others remain undetected, thus potentially underestimating the sample's toxicity.

Several studies showed that field cyanobacterial samples may cause stronger toxicity in comparison with the effects of pure toxins when tested at equivalent concentrations, indicating the presence of other toxic components (see section 2.10). These may, in addition to diverse cyanobacterial metabolites, also be toxic metals or compounds of anthropogenic origin such as pesticides, polycyclic aromatic hydrocarbons and other emerging contaminants present in complex environmental samples. Based on chemical analysis alone, it is not possible to evaluate the overall toxicity of complex mixtures. To cope with these limitations, some environmental monitoring programmes have implemented toxicity testing with bioassay(s), for example, whole effluent toxicity testing in USA and Germany (Escher \& Leusch, 2011) or the EU-supported effect-based monitoring programmes (Tousova et al., 2017).

This section firstly introduces some toxicology principles with respect to the interpretation of bioassay results; then summarises the existing experience; and critically discusses current state, limitations and recommendations 
on the applicability of bioassay for the monitoring of toxic cyanobacterial blooms with respect to possible impacts on human health. Other aspects such as testing for ecotoxicity with invertebrates or other aquatic biota are addressed only briefly because of their limitations for assessing human health end-points. This chapter does not cover other applications of bioassays such as the toxicological characterisation of individual toxins. The focus of this chapter is on bioassays employing cells, tissues or whole animals; other subcellular bioanalytical tools (ELISA or enzyme inhibitory assays such as the protein phosphatase assay) do not fit the "bioassay" criteria and are discussed in section 14.2.

\subsection{Insights into interpretation of toxicity results}

Before discussing examples and the practical applications of bioassays, those who plan to implement them in monitoring programmes need a good and common understanding of the terminology and how individual terms are used. Firstly, there is a central paradigm of toxicology, that is, "All things are poison and nothing is without poison. Solely, the dose determines that a thing is not a poison" (Paracelsus, 1493-1541). Whenever "toxicity" or "effect" is considered (e.g., animal death due to anatoxin-a neurotoxicity, microcystin-induced liver injury or decreased cell viability in vitro through cytotoxicity of cylindrospermopsin), observed effects are related to the defined test conditions. Most importantly, whether the effect manifests always depends on the dose, duration of exposure and biological system (organism). In this sense, toxicity of a compound is widely understood as causing adverse effects upon exposure as expected under normal conditions. For example, compounds like vitamins can cause adverse health effects when applied in high doses (hypervitaminoses) but vitamins are generally not considered a toxin, because, under normal conditions, an exposure leading to adverse effects is improbable (Hathcock et al., 1990; Vieth, 2007).

Current toxicology aims to establish links between the adverse health outcome (i.e., in vivo manifestation of the toxic effect) with the exposure to a toxicant through a chain of causal events formalised as an "adverse outcome pathway" (AOP; Patlewicz et al., 2015). Examples of relevant adverse health outcomes may be, for example, the death of an animal caused by a high dose of anatoxin-a, disruption of neurobehavioral abilities after chronic exposures to lower doses of anatoxin-a or eye irritation and skin rash after direct acute exposure to high doses of cyanobacterial biomass. "Toxicity" always starts at the molecular level; propagates through cells, tissues and organs; and eventually becomes apparent in vivo as systemic toxicity. The ultimate adverse outcome manifests only under specific preconditions (the toxin can reach the target, it is present in sufficiently high doses, etc.) and when the chain of events is not repaired by 
detoxification mechanisms (ADME - absorption, distribution, metabolism and excretion). An AOP relevant for cyanobacteria could be, for example, "inhibition of protein phosphatases (PPase) leading to hepatic hypertrophy and tumour promotion activity".

The interaction between the toxic chemical and its biological counterparts (molecular initiating event, MIE) can be either specific or nonspecific. Examples of specific interactions (key-lock principle) include binding of MC-LR to PPase, preferentially in liver cells, cylindrospermopsin interferences with the machinery of protein synthesis with no apparent preference to the cell type or binding of anatoxin-a to the nicotinic acetylcholine receptor on neuronal cells. Nonspecific interactions, when a chemical does not have a "specific target", are common and include, for example, the disruption of cell membrane function after the accumulation of chemicals also known as narcotic or basal toxicity, damage to proteins, membrane phospholipids or nucleic acids by reactive oxygen species or denaturation of proteins by acidic chemicals. One chemical may act through several modes of action that may lead to a single or multiple different adverse outcomes. For example, cylindrospermopsin may inhibit protein synthesis, react with DNA or induce oxidative stress leading to death or various chronic effects depending on the concentration, exposure duration, life stage, age or sex of the organism (Pichardo et al., 2017).

Toxicity of natural samples of cyanobacteria may thus be a complex response to - for example - unfavourable $\mathrm{pH}$, presence of ions and metals, saccharides, peptides (including toxins, amino acids, nucleotides, phospholipids), components of other plankton organisms (Palíková et al., 2007a; Palíková et al., 2007b) or compounds of anthropogenic origin.

\subsubsection{Bioassays in the assessment of toxic cyanobacteria}

Bioassays have primarily been developed for the testing of chemical substances based on different regulatory frameworks. Most of these tests went through a validation process with standardisation by ISO or OECD assuring good characterisation of the studied chemical and testing conditions. Bioassays are mainly based on animal testing but there is an increasing demand to reduce animal experiments and use alternative methodologies such as in silico and in vitro methods often combined into so-called integrated testing strategies (ITS) or integrated approaches to testing and assessment (IATA). Toxicity bioassays have been adapted to assess the toxicity of cyanobacterial samples. However, when testing complex samples like cyanobacterial crude extracts, the causative agent(s) inducing the toxicity cannot be easily identified.

Nevertheless, many studies explored the use of bioassays in toxicity screenings of natural cyanobacterial samples or explored their potential to 
serve as early warning tools. Positive bioassay responses could then trigger chemical analysis of cyanotoxins for more precise characterisation of the hazard. Testing with bioassays is expected to show whether the sample contains toxic substances and how toxic these substances may potentially be. Researchers can combine multiple bioassays to cover various endpoints ranging from acute cytotoxicity and mortality to complex organ or systemic effects such as reproduction toxicity. Specific in vitro assays have been used to assess mechanisms of action, potential genotoxicity or endocrine disruptive effects. Unfortunately, complex research approaches can hardly be implemented for routine monitoring or screenings of potential health hazards. However, at least four cases can be listed in which toxicity testing remains relevant:

1. if illness of animals or humans is suspected to have been caused by cyanobacteria but symptoms cannot be attributed to known cyanotoxins found by chemical analyses;

2. for testing whether specific cyanobacterial strains show toxicity not attributable to known cyanotoxins;

3. to characterise the toxicity and/or mechanism of action of newly identified toxins or congeners of previously known cyanotoxins (Fischer et al., 2010);

4. to establish the data needed to derive guideline values for the concentrations of substances to which humans may be exposed, for example, cyanotoxins in drinking-water or in waterbodies used for recreation.

\subsubsection{Nonmammalian bioassays}

Ecotoxicity assays using bacteria, protozoans, invertebrates, plants or aquatic vertebrates such as fish or amphibians have been used in many studies for detecting cyanotoxins.

Bacterial bioassays have been used to screen complex cyanobacterial samples such as the Microtox bioluminescence assay using Aliivibrio (formerly Vibrio) fischeri or Photobacterium (Vibrio) phosphoreum (Lawton et al., 1994a; Vezie et al., 1996) but with poor correlations between the reduction of the measured end-point (emitted light) and the sample's content of cyanotoxins. Poor correlations were also revealed in the bioassay with Serratia marcescens despite promising original studies with pure saxitoxins and microcystins (Lawton et al., 1994a).

Cyanobacterial samples were also tested with protozoan assays such as Tetrabymena thermophila (commercially available as Protoxkit-F; Protoxkit-F, 1998), T. pyriformis and T. thermophila (Maršálek \& Bláha, 2004) or Spirostrum ambiguum (Tarczyńska et al., 2001). Further, bioassays with aquatic or terrestrial plants were explored (Kós et al., 1995; Pflugmacher et al., 2001; Vasas et al., 2002). 
Among the bioassays with aquatic invertebrate animals, cladocerans have been widely used due to their easy maintenance, small size, wide distribution and rapid growth rates. These bioassays include standardised 24- and 48-h immobilisation assays with Daphnia magna (OECD, 2004; 2012) or commercially available test kits (Daphtoxkit-F, 1995; Ceriodaphtoxkit-F, 1995). Complex cyanobacterial samples have been tested with species of Daphnia (DeMott et al., 1991; Okumura et al., 2007; Ferrão-Filho et al., 2009), Ceriodaphnia (Maršálek \& Bláha, 2004; Okumura et al., 2007) or Moina (Ferrão-Filho et al., 2009). Further model organisms include Artemia salina (Kiviranta et al., 1991; Metcalf et al., 2002b; Beattie et al., 2003; Lindsay et al., 2006) or mosquito adults and larvae (Kiviranta et al., 1993). Also extensively used was the bioassay with larvae of fairy shrimp Thamnocephalus platyurus commercially available as Thamnotoxkit-F (MicroBioTests Inc., Mariakerke, Belgium). Box 14.3 provides more information and illustrates the difficulties and limitations in the interpretation of results for the Thamnocepalus bioassay and, correspondingly, for all invertebrate bioassays.

\section{BOX 14.3: THE THAMNOCEPHALUS PLATYURUS BIOASSAY}

The bioassay with larvae of fairy shrimp Thamnocephalus platyurus has been discussed in the past as a potential tool for routine screening of bloom toxicity. It has a number of advantages such as allowing for simple and practical use even in a format of a commercially available kit called Thamnotoxkit. It provides fast 24-h response with a possible reduction of exposure to I h (Törökné et al., 2007). The assay has been standardised (ISO, 20II), and it showed good performance in an interlaboratory test with cyanobacterial samples (Törökné et al., 2000a).

With respect to individual cyanobacterial metabolites, T. platyurus was generally reported to be highly sensitive. However, the reported IC50 values were surprisingly within a narrow - low micromolar - range for all the studied and structurally diverse cyanobacterial metabolites and toxins (including microcystins, cylindrospermopsin, microginin, aeruginosins, spumigins, cyanopeptolin, eucyclamides, oscillapeptin J) as well as fluoro-conjugated MCs or odour compounds such as sesquiterpenes (Blom et al., 200I; Blom \& Jüttner, 2005; Portmann et al., 2008; Höckelmann et al., 2009; Gademann et al., 2010; Kohler et al., 2014; Grundler et al., 2015; Mazur-Marzec et al., 2015; Scherer et al., 2016; Bober \& Bialczyk, 2017), while the assay was reported to be less sensitive to the neurotoxin anatoxin-a (Sieroslawska, 2013). With regard to screening of complex bloom samples, the literature provides a conflicting picture. One study (Tarczyńska et al., 2000) compared seven extracts and found 
a statistically significant relationship between the observed toxicity and the microcystin-LR content. On the other hand, several other studies showed high toxicity in $T$. platyurus irrespective of the content of major cyanotoxins (Maršálek et al., 2000; Törökné et al., 2000a; Törökné et al., 2000b; Keil et al., 2002; Nałęcz-Jawecki et al., 2002; Maršálek \& Bláha, 2004; Törökné et al., 2007; Ács et al., 2013; Sieroslawska, 2013).

Despite apparently high sensitivity of the $T$. platyurus assay, its implementation into routine monitoring of bloom toxicity would not provide a major added value to toxin analyses with chemical or biochemical methods because it is generally not able to discriminate between toxic (in the sense of "containing cyanotoxins") and nontoxic cyanobacterial samples. Further, its responses were not correlated with toxicity observed with other organisms, including mouse in vivo assay (Tarczyńska et al., 2000; Tarczyńska et al., 200l).

In addition to invertebrates, fish and frog bioassays have also been explored. With respect to ethical concerns associated with the use of adult fish (namely, zebrafish Danio rerio, Japanese medaka Oryzias latipes or fathead minnow Pimephales promelas), assays with fish embryos have become popular (Berry et al., 2009). The zebrafish Danio rerio fish embryo toxicity (FET) assay has been standardised (OECD, 2013). The embryo fish tests were used in many studies of cyanobacteria (Oberemm et al., 1999; Wang et al., 2005; Lecoz et al., 2008), but some concerns related to the uptake of toxins through the chorion barrier or limited toxicokinetics in developing embryos have been raised. With respect to amphibians, frog embryo teratogenesis assay Xenopus (FETAX) (ASTM, 2017) using Xenopus laevis (African clawed frog) has also been explored but showed rather low correlation with the content of known cyanotoxins (Oberemm et al., 1999; Fischer \& Dietrich, 2000; Burýšková et al., 2006).

\subsubsection{Mouse bioassay}

For many years, the mouse in vivo bioassay was used to determine toxicity of cyanobacterial blooms (Carmichael, 1992; Fastner et al., 2003; SoteroSantos et al., 2006) or to detect phycotoxins in shellfish (Box 14.4). In testing of toxic cyanobacteria, male Swiss Albino mice were the most commonly used animals. Effects are assessed after intraperitoneal injection (i.p.) of $0.1-1.0 \mathrm{~mL}$ of a lysate of the cyanobacterial sample. Mice are observed for $24 \mathrm{~h}$, sacrificed by an approved method and submitted to postmortem examination of tissue injury (Falconer, 1993). The observation period could be extended when the possibility of protracted symptom manifestation is expected, as it may be the case with cylindrospermopsin (see Chapter 2.2). 
When more than one type of cyanotoxin is present, the more rapid-acting toxin may mask the symptoms of the others. Acute toxicity is expressed as the dose at which one half of the treated animals has died within the determined time period, that is, usually $24 \mathrm{~h}\left(\mathrm{LD}_{50}\right.$ in mg extract dry weight/ $\mathrm{kg}$ mouse body weight). According to the Globally Harmonized System of Classification and Labelling of Chemicals (GHS; UNECE, 2017), five acute toxicity categories are recognised based on oral $\mathrm{LD}_{50}(\mathrm{mg} / \mathrm{kg}$ b). The most toxic is Category 1 with oral $\mathrm{LD}_{50}<5 \mathrm{mg} / \mathrm{kg}$ bw, while for Category 5 acute oral $\mathrm{LD}_{50}$ ranges between 2000 and $5000 \mathrm{mg} / \mathrm{kg}$. $\mathrm{LD}_{50}$ higher than 5000 $\mathrm{mg} / \mathrm{kg} \mathrm{b}$ is considered as absence of acute toxicity.

\section{BOX 14.4: MOUSE BIOASSAY IN TOXICITY TESTING OF MARINE BIVALVES}

Biotoxins produced by marine (phyto)plankton which may accumulate in seafood remain a major public health issue in some parts of the world. Some regulatory approaches also refer to the use of mouse bioassays, but the bioassay is no longer used very often with regard to recent technology developments of chemical-specific analytical methods as well as ethical concerns.

For example, okadaic acid (so-called OA toxins, that is, OA and its analogues), the dinophysis toxins (DTXI, DTX2 and DTX3) can be found in tissues of molluscs such as oysters, mussels, scallops and clams, and cause diarrhetic shellfish poisoning (DSP). The inhibition of serine/threonine phosphoprotein phosphatases is their main mode of action, similar to, for example, cyanobacterial microcystins. To control for DSP, the mouse and the rat in vivo bioassays have been official reference methods in the EU (Commission Regulation (EC) No. 2074/20054) using the intraperitoneal (i.p.) injection of mussel tissue extract followed by 24-h monitoring of test animals. Despite the advantages of the bioassay (whole-organism toxicity response, no need for complex analytical equipment), an official opinion of the European Food Safety Authority (EFSA, 2009) highlighted several disadvantages, that is, a high variability and labour demand, needs of specialised animal facilities, false-positive results due to interferences with, for example, free fatty acids, not selective for solely the OA-group toxins, not quantitative, inappropriate i.p. administration route and ethical reasons. The EFSA therefore concluded that they are inappropriate for assessing compliance to the regulatory limit set for seafood by the EU. The same report also concluded that the phosphoprotein phosphatase assays and LC-MS/(MS)-based methods have the greatest potential to replace the mammalian assays, due to sufficient sensitivity and satisfactory validation performance. 
A recommendation to replace the mouse bioassay for the assessment of broader groups of marine toxins (AZA, BTX, DA, OA, PTX, SXT, YTY) by alternative chemico-physical methods such as LC/MS has been prepared by German Federal Institute for Risk Assessment (BfR, 2005). The mouse bioassay is only envisaged as an additional analytical step when a positive result has been obtained and further clarification is needed in the interests of consumer protection (suitability of the test results for use in court, etc.). The LC/MS method has, for example, been recognised by the New Zealand Food Safety Authority (FSA) as an official method and successfully tested in an interlaboratory trial.

Nevertheless, for control of marine paralytic shellfish poison (PSP) biotoxins, the mouse bioassay remains a standardised method of the European Union Reference Laboratory for Marine Biotoxins (EURLMB) at Agencia Española de Consumo, Seguridad Alimentaria y Nutrición (AECOSAN, 2014), which is in line with the Association of Official Analytical Chemists Official Method (AOAC, 2005a). The mouse bioassay is mentioned in the context of PSP biotoxins in the food of animal origin within the frame of the European Regulation (EC) N ${ }^{\circ} 853 / 2004$, and related methodological regulations (Commission Regulation (EC) $N^{\circ} 2074 / 2005$ amended by EC $N^{\circ}$ 1664/2006, EC N ${ }^{\circ}$ 1244/2007 and EU N ${ }^{\circ}$ 15/201I).

Among the other standardised methods for marine biotoxin detection, HPLC method - so-called Lawrence method (Lawrence et al., 2005) - is mentioned in the EU regulation and immunochemistry approaches remain to be discussed as an alternative for the future, after undergoing validation through interlaboratory exercises (Burrell et al., 2016; Dorantes-Aranda et al., 2018; Turner et al., 2019).

Using this mammalian model, observations of the target organs can help extrapolating to the effects in humans. However, the mouse bioassay is generally done through intraperitoneal injection, which may not be the most relevant route of exposure for such extrapolation to humans. Also, other aspects such as low sensitivity and selectivity, high rates of false positives, variability and ethical concerns created a demand for alternative tests. Nevertheless, in some countries, the mouse bioassays can still provide some guidance for managers, for example, to determine toxicity of marine bivalves considered for human consumption or when a bloom occurs in the raw water but chemical analyses do not reveal any known cyanotoxins.

For deriving WHO guideline values or regulatory standards issued by public authorities worldwide, if data on human populations are inadequate or insufficient, a preferred basis is chronic exposure studies with rodents, 
with toxin applied orally, that is, via food, drinking-water or gavage, and animal health observed during extended periods of time, particularly those based on standardised guidelines such as OECD Test No. 408 (Repeated Dose 90-Day Oral Toxicity Study in Rodents), Test No. 407 (Repeated Dose 28-day Oral Toxicity Study in Rodents). One-generation reproduction studies (OECD Tests No. 415 or No. 443) are particularly comprehensive and thus valuable, but rare because of high costs and demands. In practice, toxicological data from such chronic whole-animal studies may not be available, and risk assessors need to include other toxicological data, including those from acute oral exposure tests (e.g., OECD Tests No. 420, 423 or 425$)$. These and further guidelines are freely available under https:// www.oecd-ilibrary.org/environment (Book Series).

\subsubsection{In vitro assays for determining toxicity and genotoxicity}

In vitro bioassays using cell cultures have received wide attention for replacing animal tests. However, a single in vitro bioassay alone cannot cover all of the biological targets or processes found within an organism. Therefore, a hierarchic in vitro test strategy is necessary for characterising the type of toxicity induced by the unknown toxicants as proposed in different strategic documents and recommendations for water quality assessment (enHealth, 2012; Grummt et al., 2013). The following paragraphs provide examples as well as a summation of the advantages and disadvantages of in vitro bioassays, which could form part of such a hierarchic in vitro test strategy specifically for cyanotoxins.

The hepatotoxicity of microcystins triggered the use of hepatocytes (liver cells) from different fish or mammalian species (Aune \& Berg, 1986). Freshly isolated hepatocytes may - for a certain period - retain necessary liver characteristics like active bile acid transport or phase I and II metabolising enzymes, and many studies showed high sensitivity to cyanotoxins in rat or mouse hepatocytes (Fladmark et al., 1998; Li et al., 2001; Boaru et al., 2006). A need for fresh isolation can be overcome by using cryopreserved hepatocytes, preferably of human origin or a specific cell line such as HepaRG (Bazin et al., 2010), which maintains most of the in vivo features. A basic prerequisite for microcystin uptake into the cells seems to be the presence of certain organic anion-transporting polypeptides (OATP) within the cell membrane, as a study with genetically modified OATPcompetent HEK293 cells has shown (Fischer et al., 2010). Many other cell lines, such as HepG2, CaCo2, and V79, have been used to study cyanobacterial samples (Lawton et al., 1994a; Fastner et al., 2003; Žegura et al., 2003; Lankoff et al., 2006; Žegura et al., 2008; Fischer et al., 2010). Besides having a tumoral origin in most cases, these cell lines may lack certain metabolic enzymes important for activation and in particular for 
detoxification; therefore, they are prone to giving misleading results, thus limiting their informative value.

For assessing neurotoxicity, the Neuro-2A neuroblastoma cell test has been developed and used for monitoring of saxitoxins in freshwater cyanobacteria (Gallacher \& Birkbeck, 1992; Humpage et al., 2007). Endocrine activity can be examined by oestrogen or androgen receptor-specific reporter gene assays (OECD, 2016a; b) and steroidogenesis assay in H295R cells (OECD, 2011). Within the OECD framework, these in vitro tests are part of the first tier and are considered as a screening tool, which is not sufficient to categorise a substance as an endocrine disruptor.

Genotoxicity and mutagenicity are important end-points for human and environmental hazard evaluation, and a number of assays, often adopted as ISO or OECD guidelines, are used in the assessment of toxic cyanobacteria. Among the bacterial assays, the Ames assay (OECD, 1997) showed the mutagenicity of various cyanobacterial extracts (Huang et al., 2007), while pure cyanotoxins were mostly negative in the assay (Z̈egura, 2016). Palus et al. (2007) showed genotoxicity of various extracts or cyanobacterial toxins in SOS chromo test with Escherichia coli PQ37 but negative results were reported with the SOS/umu-test (ISO, 2000) with Salmonella Typhimurium TA1535/pSK1002. However, the caveat of many publications is that cytotoxicity (resulting in DNA fragmentation) is not accounted for, which may lead to false positives or overestimation of the relevance of genotoxicity.

With regard to eukaryotic cell models, the mammalian cell gene mutation assay (OECD, 2016c) demonstrated that MC-LR preferentially induces clastogenic effects on DNA rather than point mutations (Zhan et al., 2004). Various cyanobacterial extracts induced micronuclei in the in vitro cytokinesis-block micronucleus assay (micronucleus test) (OECD, 2016d) in human lymphocytes (Palus et al., 2007). Cylindrospermopsin was shown to have clastogenic and aneugenic activities in human WIL2-NS lymphoblastoids (Humpage et al., 2000) and hepatic cells (Bazin et al., 2010; Štraser et al., 2011). The comet assay, also known as the single-cell gel electrophoresis (SCGE) assay - which detects DNA damage (in the form of strand breaks, or other lesions that are converted into strand breaks under alkaline conditions) and DNA repair activity, and gives an indication of the genotoxic insult - has gained broad attention in genetic toxicology of toxic cyanobacteria (Ding et al., 1999; Žegura et al., 2003; Humpage et al., 2005; Palus et al., 2007). Cyanobacterial extracts (Palus et al., 2007) and several pure cyanotoxins, including MC-LR, cylindrospermopsin and nodularin, have been shown to induce DNA strand breaks (see Žegura et al., 2011 for a review). MC-LR induces transiently present DNA strand breaks that can be repaired and most probably occur indirectly due to oxidative stress (Žegura, 2016), while CYN induces DNA strand breaks in metabolically active cells (Humpage et al., 2005; Hercog et al., 2017). 
Since the 2010s, hazard identification shifted towards mechanistic assessment that enables predictions of adverse outcome pathways (AOPs) (Ankley et al., 2010; Schroeder et al., 2016). The "omic" biomarker approaches ( $\mathrm{Li}$ et al., 2017) using high-throughput molecular biology and mass spectrometry tools allow us to identify biological targets and pathways affected by the toxic compounds, including cyanotoxins (Štraser et al., 2013; Hercog et al., 2017). The "omic" biomarkers complement the standard toxicity and genotoxicity assays but how to use these complex data in the risk assessment procedure remains to be clarified.

\subsubsection{Summary}

In summary, toxicity testing of complex samples such as cyanobacterial blooms, raw or tap water provides rather minor additional value to current risk assessment of cyanobacterial toxicity, particularly where known cyanotoxins are present and sensitive instrumental methods for the detection of multiple toxins, as discussed above, are available (Meriluoto et al., 2017; Zervou et al., 2017). Alternatively, immunoassays such as ELISA or enzyme-inhibitory assays may serve for semiquantitative and sufficiently selective screenings. Toxicity testing has its place in bloom situations in which targeted analyses do not reveal any known cyanotoxins and uncertainty about the safety of the water remains, as, for example, in the case of a South Australian water supply with an unidentified toxin from Phormidium (Baker et al., 2001). In such a situation, the results of bioassays with mammalian cells in vitro or animals in vivo (mouse test) are most likely to provide some immediate guidance for managers regarding the acute toxicity of water.

Bioassays are important for further exploring the effects of yet unknown or not sufficiently characterised substances produced by cyanobacteria. A wide range of bioassays is available at many different levels from molecular to cell cultures or whole organisms. However, one single test will rarely be sufficient to fully characterise the toxicity of a cyanobacterial bloom; this usually requires a set of assays. Bioassays can give rapid responses, but a thorough validation process is needed for testing their performances, particularly if they are to be applied in the investigation of complex samples such as blooms, raw or treated drinking-water. In vitro bioassays are useful for developing an understanding of the biochemical processes underlying toxicity, whereas in vivo studies, despite technical and ethical concerns, continue to have a key role in supporting risk assessment, including in guideline value derivation. For the identification of unknown toxic agents from cyanobacterial blooms, effect-based monitoring or effect-directed analyses (EDA) (Escher \& Leusch, 2011; Tousova et al., 2017) efficiently combine both bioassays and chemical analyses. 


\section{REFERENCES}

Ács A, Kovács AW, Csepregi JZ, Törő N, Kiss G, Győri J et al. (2013). The ecotoxicological evaluation of Cylindrospermopsis raciborskii from Lake Balaton (Hungary) employing a battery of bioassays and chemical screening. Toxicon. 70:98-106.

AECOSAN (2014). Standard Operating Procedure for PSP toxins by Mouse Bioassay. Vigo: Agencia Española de Consumo, Seguridad Alimentaria y Nutrición. http://www.aecosan.msssi.gob.es/.

Alfonso A, Louzao M, Vieytes M, Botana L (1994). Comparative study of the stability of saxitoxin and neosaxitoxin in acidic solutions and lyophilized samples. Toxicon. 32:1593-1598.

Almuhtaram H, Cui Y, Zamyadi A, Hofmann R (2018). Cyanotoxins and cyanobacteria cell accumulations in drinking water treatment plants with a low risk of bloom formation at the source. Toxins. 10:430.

Altaner S, Puddick J, Wood SA, Dietrich DR (2017). Adsorption of ten microcystin congeners to common laboratory-ware Is solvent and surface dependent. Toxins. 9:129.

Ankley GT, Bennett RS, Erickson RJ, Hoff DJ, Hornung MW, Johnson RD et al. (2010). Adverse outcome pathways: a conceptual framework to support ecotoxicology research and risk assessment. Environ Toxicol Chem. 29:730-741.

AOAC (2005a). Official method 959.08: paralytic shellfish poison - biological method. Gaithersburg (MD): Association of Official Analytical Chemists International. http://www.eoma.aoac.org/methods/.

AOAC (2005b). Official method 2005.06 paralytic shellfish poisoning toxins in shellfish. Gaithersburg (MD): Association of Official Analytical Chemists International. http://www.eoma.aoac.org/methods/.

AOAC (2011). Official method 2011.02 determination of paralytic shellfish poisoning toxins in mussels, clams, oysters and scallops. Gaithersburg (MD): Association of Official Analytical Chemists International. http://www.eoma.aoac.org/methods/.

ASTM (2017). E1439-12: standard guide for conducting the Frog Embryo Teratogenesis Assay-Xenopus (FETAX). ASTM Volume 1106, Environmental; Biological effects and environ fate; Industrial biotechnology. West Conshohocken (PA): American Society for Testing and Materials.

Aune T, Berg K (1986). Use of freshly prepared rat hepatocytes to study toxicity of blooms of the blue-green algae Microcystis aeruginosa and Oscillatoria agardbii. J Toxicol Environ Health Part A Current Issues. 19:325-336.

Baker PD, Steffensen DA, Humpage AR, Nicholson BC, Falconer IR, Lanthois B et al. (2001). Preliminary evidence of toxicity asociated with the benthic cyanobacetrium Phormidium in South Australia. Environ Toxicol. 16:506-511.

Barco M, Lawton LA, Rivera J, Caixach J (2005). Optimization of intracellular microcystin extraction for their subsequent analysis by high-performance liquid chromatography. J Chromatogr A. 1074:23-30.

Bazin E, Mourot A, Humpage AR, Fessard V (2010). Genotoxicity of a freshwater cyanotoxin, cylindrospermopsin, in two human cell lines: Caco-2 and HepaRG. Environ Mol Mutagen. 51:251-259.

Beattie KA, Ressler J, Wiegand C, Krause E, Codd GA, Steinberg CE et al. (2003). Comparative effects and metabolism of two microcystins and nodularin in the brine shrimp Artemia salina. Aquat Toxicol. 62:219-226. 
Berry JP, Gibbs PDL, Schmale MC, Saker ML (2009). Toxicity of cylindrospermopsin, and other apparent metabolites from Cylindrospermopsis raciborskii and Aphanizomenon ovalisporum, to the zebrafish (Danio rerio) embryo. Toxicon. 53:289-299.

BfR (2005). Mouse bioassay not suitable as a reference method for the regular analysis of algae toxins in mussels. Berlin: Bundesanstalt für Risikobewertung:7 pp.

Birbeck J, Westrick J, O’Neill G, Spies B, Szlag D (2019). Comparative analysis of microcystin prevalence in Michigan lakes by online concentration LC/MS/MS and ELISA. Toxins. 11:13.

Blom JF, Jüttner F (2005). High crustacean toxicity of microcystin congeners does not correlate with high protein phosphatase inhibitory activity. Toxicon. 46:465-470.

Blom JF, Robinson JA, Jüttner F (2001). High grazer toxicity of [D-Asp(3) (E)-Dhb(7)] microcystin-RR of Planktothrix rubescens as compared to different microcystins. Toxicon. 39:1923-1932.

Boaru DA, Dragoş N, Schirmer K (2006). Microcystin-LR induced cellular effects in mammalian and fish primary hepatocyte cultures and cell lines: a comparative study. Toxicology. 218:134-148.

Bober B, Bialczyk J (2017). Determination of the toxicity of the freshwater cyanobacterium Woronichinia naegeliana (Unger) Elenkin. J Appl Phycol. 29:1355-1362.

Brown A, Foss A, Miller MA, Gibson Q (2018). Detection of cyanotoxins (microcystins/nodularins) in livers from estuarine and coastal bottlenose dolphins (Tursiops truncatus) from Northeast Florida. Harmful Algae. 76:22-34.

Burrell S, Crum S, Foley B, Turner AD (2016). Proficiency testing of laboratories for paralytic shellfish poisoning toxins in shellfish by QUASIMEME: a review. Trends Anal Chem. 75:10-23.

Burýšková B, Hilscherová K, Babica P, Vršková D, Maršálek B, Bláha L (2006). Toxicity of complex cyanobacterial samples and their fractions in Xenopus laevis embryos and the role of microcystins. Aquat Toxicol. 80:346-354.

Caixach J, Flores C, Spoof L, Meriluoto J, Schmidt W, Mazur-Marzec H et al. (2017). Liquid chromatography-mass spectrometry. In: Meriluoto J, Spoof L, Codd G et al., editors: Handbook of cyanobacterial monitoring and cyanotoxin analysis. Chichester: John Wiley \& Sons:218-257.

Carmichael WW (1992). Cyanobacteria secondary metabolites - the cyanotoxins. J Appl Microbiol. 72:445-459.

Catanante G, Espin L, Marty J-L (2015). Sensitive biosensor based on recombinant PP1 $\alpha$ for microcystin detection. Biosens Bioelectron. 67:700-707.

Colas S, Duval C, Marie B (2020). Toxicity, transfer and depuration of anatoxina (cyanobacterial neurotoxin) in medaka fish exposed by single-dose gavage. Aquatic Toxicol. 222:105422.

de la Cruz AA, Hiskia A, Kaloudis T, Chernoff N, Hill D, Antoniou MG et al. (2013). A review on cylindrospermopsin: the global occurrence, detection, toxicity and degradation of a potent cyanotoxin. Environ Sci Process Impacts. 15:1979-2003.

Dell'Aversano C, Eaglesham GK, Quilliam MA (2004). Analysis of cyanobacterial toxins by hydrophilic interaction liquid chromatography-mass spectrometry. J Chromatogr A. 1028:155-164.

DeMott WR, Zhang QX, Carmichael WW (1991). Effects of toxic cyanobacteria and purified toxins on the survival and feeding of a copepod and three species of Daphnia. Limnol Oceanogr. 36:1346-1357. 
Ding WX, Shen HM, Zhu HG, Lee BL, Ong CN (1999). Genotoxicity of microcystic cyanobacteria extract of a water source in China. Mut Res Gen Toxicol Environ Mutagen. 442:69-77.

Dorantes-Aranda JJ, Tan JY, Hallegraeff GM, Campbell K, Ugalde SC, Harwood DT et al. (2018). Detection of paralytic shellfish toxins in mussels and oysters using the qualitative neogen lateral-flow immunoassay: an interlaboratory study. J AOAC Int. 101:468-479.

Dörr FA, Rodríguez V, Molica R, Henriksen P, Krock B, Pinto E (2010). Methods for detection of anatoxin-a (s) by liquid chromatography coupled to electrospray ionization-tandem mass spectrometry. Toxicon. 55:92-99.

Eangoor P, Indapurkar AS, Vakkalanka MD, Knaack JS (2019). Multiplexed ELISA screening assay for nine paralytic shellfish toxins in human plasma. Analyst. 144:4702-4707.

EFSA (2009). Scientific opinion: marine biotoxins in shellfish-saxitoxin group. EFSA J. 1019:1-76.

enHealth (2012). Environmental health risk assessment. Canberra: Environmental Health Standing Committee:244 pp. https://www.health.gov.au.

Escher B, Leusch F (2011). Bioanalytical tools in water quality assessment. London: IWA publishing. $272 \mathrm{pp}$.

Falconer IR (1993). Measurement of toxins from blue-green algae in water and foodstuffs. In: Falconer IR, editors: Algal toxins in seafood and drinking water. London: Academic Press.

Fastner J, Heinze R, Humpage AR, Mischke U, Eaglesham GK, Chorus I (2003). Cylindrospermopsin occurrence in two German lakes and preliminary assessment of toxicity and toxin production of Cylindrospermopsis raciborskii (Cyanobacteria) isolates. Toxicon. 42:313-321.

Fayad PB, Roy-Lachapelle A, Duy SV, Prévost M, Sauvé S (2015). On-line solid-phase extraction coupled to liquid chromatography tandem mass spectrometry for the analysis of cyanotoxins in algal blooms. Toxicon. 108:167-175.

Ferrão-Filho AdS, Soares MCS, de Freitas Magalhães V, Azevedo SM (2009). Biomonitoring of cyanotoxins in two tropical reservoirs by cladoceran toxicity bioassays. Ecotoxicol Environ Safety. 72:479-489.

Fischer A, Höger SJ, Stemmer K, Feurstein D, Knobeloch D, Nussler A et al. (2010). The role of organic anion transporting polypeptides (OATPs/SLCOs) in the toxicity of different microcystin congeners in vitro: a comparison of primary human hepatocytes and OATP-transfected HEK293 cells. Toxicol Appl Pharmacol. 245:9-20.

Fischer WJ, Dietrich DR (2000). Toxicity of the cyanobacterial cyclic heptapeptide toxins microcystin-LR and-RR in early life-stages of the African clawed frog (Xenopus laevis). Aquat Toxicol. 49:189-198.

Fladmark KE, Serres MH, Larsen NL, Yasumoto T, Aune T, Døskeland SO (1998). Sensitive detection of apoptogenic toxins in suspension cultures of rat and salmon hepatocytes. Toxicon. 36:1101-1114.

Foss AJ, Aubel MT (2013). The extraction and analysis of cylindrospermopsin from human serum and urine. Toxicon. 70:54-61.

Foss AJ, Aubel MT (2015). Using the MMPB technique to confirm microcystin concentrations in water measured by ELISA and HPLC (UV, MS, MS/MS). Toxicon. 104:91-101. 
Gademann K, Portmann C, Blom JF, Zeder M, Jüttner F (2010). Multiple toxin production in the cyanobacterium Microcystis: isolation of the toxic protease inhibitor cyanopeptolin 1020. J Nat Prod. 73:980-984.

Gaget V, Lau M, Sendall B, Froscio S, Humpage AR (2017). Cyanotoxins: which detection technique for an optimum risk assessment? Water Res. 118:227-238.

Gallacher S, Birkbeck T (1992). A tissue culture assay for direct detection of sodium channel blocking toxins in bacterial culture supernates. FEMS Microbiol Lett. 92:101-107.

Greer B, McNamee SE, Boots B, Cimarelli L, Guillebault D, Helmi K et al. (2016). A validated UPLC-MS/MS method for the surveillance of ten aquatic biotoxins in European brackish and freshwater systems. Harmful Algae. 55:31-40.

Grummt T, Kuckelkorn J, Bahlmann A, Baumstark-Khan C, Brack W, Braunbeck T et al. (2013). Tox-Box: securing drops of life-an enhanced health-related approach for risk assessment of drinking water in Germany. Environ Sci Europe. 25:27.

Grundler V, Faltermann S, Fent K, Gademann K (2015). Preparation of fluorescent microcystin derivatives by direct arginine labelling and their biological evaluation. ChemBioChem. 16:1657-1662.

Haddad SP, Bobbitt JM, Taylor RB, Lovin LM, Conkle JL, Chambliss CK et al. (2019). Determination of microcystins, nodularin, anatoxin-a, cylindrospermopsin, and saxitoxin in water and fish tissue using isotope dilution liquid chromatography tandem mass spectrometry. J Chromatogr A. 1599:66-74.

Harrison K, Johnson S, Turner AD (2016). Application of rapid test kits for the determination of paralytic shellfish poisoning (PSP) toxins in bivalve molluscs from Great Britain. Toxicon. 119:352-361.

Hathcock JN, Hattan DG, Jenkins MY, McDonald JT, Sundaresan PR, Wilkening VL (1990). Evaluation of vitamin A toxicity. Am J Clin Nutr. 52:183-202.

Hercog K, Maisanaba S, Filipič M, Jos Á, Cameán AM, Žegura B (2017). Genotoxic potential of the binary mixture of cyanotoxins microcystin-LR and cylindrospermopsin. Chemosphere. 189:319-329.

Heussner AH, Winter I, Altaner S, Kamp L, Rubio F, Dietrich DR (2014). Comparison of two ELISA-based methods for the detection of microcystins in blood serum. Chem Biol Interact. 223:10-17.

Höckelmann C, Becher PG, von Reuß SH, Jüttner F (2009). Sesquiterpenes of the geosmin-producing cyanobacterium Calothrix PCC 7507 and their toxicity to invertebrates. Zeitschrift für Naturforschung C. 64:49-55.

Huang W-J, Lai C-H, Cheng Y-L (2007). Evaluation of extracellular products and mutagenicity in cyanobacteria cultures separated from a eutrophic reservoir. Sci Tot Environ. 377:214-223.

Humpage A, Magalhaes V, Froscio S (2010). Comparison of analytical tools and biological assays for detection of paralytic shellfish poisoning toxins. Anal Bioanal Chem. 397:1655-1671.

Humpage AR, Fenech M, Thomas P, Falconer IR (2000). Micronucleus induction and chromosome loss in transformed human white cells indicate clastogenic and aneugenic action of the cyanobacterial toxin, cylindrospermopsin. Mutat Res. 472:155-161.

Humpage AR, Fontaine F, Froscio S, Burcham P,Falconer IR (2005). Cylindrospermopsin genotoxicity and cytotoxicity: Role of cytochrome P-450 and oxidative stress. J Toxicol Environ Health Part A. 68:739-753. 
Humpage AR, Ledreux A, Fanok S, Bernard C, Briand JF, Eaglesham G et al. (2007). Application of the neuroblastoma assay for paralytic shellfish poisons to neurotoxic freshwater cyanobacteria: interlaboratory calibration and comparison with other methods of analysis. Environ Toxicol Chem. 26:1512-1519.

Hyenstrand P, Metcalf JS, Beattie KA, Codd GA (2001). Effects of adsorption to plastics and solvent conditions in the analysis of the cyanobacterial toxin microcystinLR by high performance liquid chromatography. Water Res. 35:3508-3511.

Imhof L, Schmidt W (2017). SOP20: extraction and chemical analysis of saxitoxin and analogues water. In: Meriluoto J, Spoof L, Codd GA et al., editors: Handbook of cyanobacterial monitoring and cyanotoxin analysis. Chichester: John Wiley \& Sons.

ISO (2000). ISO 13829. Determination of the genotoxicity of water and waste water using the umu-test. Geneva: International Organization for Standardization.

ISO (2005). ISO 20179. Determination of microcystins: method using solid phase extraction (SPE) and high performance liquid chromatography (HPLC) with ultraviolet (UV) detection. Geneva: International Organization for Standardization.

ISO (2011). ISO 14380. Determination of the acute toxicity to Thamnocephalus platyurus (Crustacea, Anostraca). Geneva: International Organization for Standardization.

ISO (2015). ISO 9001. Quality management systems - Requirements. Geneva: International Organization for Standardization.

James KJ, Furey A, Sherlock IR, Stack MA, Twohig M, Caudwell FB et al. (1998) Sensitive determination of anatoxin-a, homoanatoxin-a and their degradation products by liquid chromatography with fluorimetric detection. J Chromatogr A 798:147-157.

John N, Baker L, Ansell BR, Newham S, Crosbie ND , Jex AR (2019). First report of anatoxin-a producing cyanobacteria in Australia illustrates need to regularly up-date monitoring strategies in a shifting global distribution. Sci Rep. 9:1-9.

Kamp L, Church JL, Carpino J, Faltin-Mara E, Rubio F (2016). The effects of water sample treatment, preparation, and storage prior to cyanotoxin analysis for cylindrospermopsin, microcystin and saxitoxin. Chem-Biol Interact. 246:45-51.

Keil C, Forchert A, Fastner J, Szewzyk U, Rotard W, Chorus I et al. (2002). Toxicity and microcystin content of extracts from a Planktothrix bloom and two laboratory strains. Water Res. 36:2133-2139.

Kim J, Lim J, Lee C (2013). Quantitative real-time PCR approaches for microbial community studies in wastewater treatment systems: applications and considerations. Biotechnol Adv. 31:1358-1373.

Kiviranta J, Abdel-Hameed A, Sivonen K, Niemelä S, Carlberg G (1993). Toxicity of cyanobacteria to mosquito larvae-screening of active compounds. Environ Toxicol. 8:63-71.

Kiviranta J, Sivonen K, Niemelä S, Huovinen K (1991). Detection of toxicity of cyanobacteria by Artemia salina bioassay. Environ Toxicol. 6:423-436.

Kohler E, Grundler V, Häussinger D, Kurmayer R, Gademann K, Pernthaler J et al. (2014). The toxicity and enzyme activity of a chlorine and sulfate containing aeruginosin isolated from a non-microcystin-producing Planktothrix strain. Harmful Algae. 39:154-160.

Kós P, Gorzo G, Suranyi G, Borbely G (1995). Simple and efficient method for isolation and measurement of cyanobacterial hepatotoxins by plant tests (Sinapis alba L.). Anal Biochem. 225:49-53. 
Krause E, Wenschuh H, Jungblut PR (1999). The dominance of arginine-containing peptides in MALDI-derived tryptic mass fingerprints of proteins. Anal Chem. 71:4160-4165.

Lankoff A, Wojcik A, Fessard V, Meriluoto J (2006). Nodularin-induced genotoxicity following oxidative DNA damage and aneuploidy in HepG2 cells. Toxicol Lett. 164:239-248.

Lawrence J, Menard C, Cleroux C (1995). Evaluation of prechromatographic oxidation for liquid chromatographic determination of paralytic shellfish poisons in shellfish. J AOAC Int. 78:514-520.

Lawrence JF, Niedzwiadek B, Menard C (2005). Quantitative determination of paralytic shellfish poisoning toxins in shellfish using prechromatographic oxidation and liquid chromatography with fluorescence detection: collaborative study. J AOAC Int. 88:1714-1732.

Lawton L, Beattie K, Hawser S, Campbell D, Codd G (1994a). Evaluation of assay methods for the determination of cyanobacterial hepatotoxicity. In: Codd GA, Jefferies T, Keevil C et al., editors: Detection methods for cynobacterial toxins. Cambridge, UK: The Royal Society of Chemistry:111-116.

Lawton LA, Edwards C, Codd GA (1994b). Extraction and High-Performance Liquid Chromatography method for the determination of microcystins in raw and treated waters. Analyst. 119:1525-1530.

Lecoz N, Malécot M, Quiblier C, Puiseux-Dao S, Bernard C, Crespeau F et al. (2008). Effects of cyanobacterial crude extracts from Planktothrix agardhii on embryolarval development of medaka fish, Oryzias latipes. Toxicon. 51:262-269.

Li H-H, Chen R, Hyduke DR, Williams A, Frötschl R, Ellinger-Ziegelbauer H et al. (2017). Development and validation of a high-throughput transcriptomic biomarker to address 21st century genetic toxicology needs. Proc Natl Acad Sci USA. 114:E10881-E10889.

Li X, Cheng R, Shi H, Tang B, Xiao H, Zhao G (2016). A simple highly sensitive and selective aptamer-based colorimetric sensor for environmental toxins microcystinLR in water samples. J Hazard Mat. 304:474-480.

Li X, Liu Y, Song L (2001). Cytological alterations in isolated hepatocytes from common carp (Cyprinus carpio L.) exposed to microcystin-LR. Environ Toxicol. 16:517-522.

Lindsay J, Metcalf J, Codd G (2006). Protection against the toxicity of microcystin-LR and cylindrospermopsin in Artemia salina and Daphnia spp. by pre-treatment with cyanobacterial lipopolysaccharide (LPS). Toxicon. 48:995-1001.

Maršálek B, Bláha L (2004). Comparison of 17 biotests for detection of cyanobacterial toxicity. Environ Toxicol. 19:310-317.

Maršálek B, Bláha L, Hindák F (2000). Review of toxicity of cyanobacteria in Slovakia. Biologia. 55:645-652.

Mazur-Marzec H, Sutryk K, Hebel A, Hohlfeld N, Pietrasik A, Błaszczyk A (2015). Nodularia spumigena peptides-Accumulation and effect on aquatic invertebrates. Toxins. 7:4404-4420.

McCall JR, Holland WC, Keeler DM, Hardison DR, Litaker RW (2019). Improved accuracy of saxitoxin measurement using an optimized enzyme-linked immunosorbent assay. Toxins. 11:632.

McNamee SE, Elliott CT, Greer B, Lochhead M, Campbell K (2014). Development of a planar waveguide microarray for the monitoring and early detection of five harmful algal toxins in water and cultures. Environ Sci Technol.48:13340-13349. 
Meriluoto J, Spoof L, Codd GA, EU-COST (2017). Handbook of cyanobacterial monitoring and cyanotoxin analysis. Chichester: John Wiley \& Sons:576 pp.

Metcalf JS, Beattie KA, Saker ML, Codd GA (2002a). Effects of organic solvents on the high performance liquid chromatographic analysis of the cyanobacterial toxin cylindrospermopsin and its recovery from environmental eutrophic waters by solid phase extraction. FEMS Microbiol Lett. 216:159-164.

Metcalf JS, Codd GA (2000). Microwave oven and boiling waterbath extraction of hepatotoxins from cyanobacterial cells. FEMS Microbiol Lett. 184:241-246.

Metcalf JS, Lindsay J, Beattie K, Birmingham S, Saker M, Törökné AK et al. (2002b). Toxicity of cylindrospermopsin to the brine shrimp Artemia salina: comparisons with protein synthesis inhibitors and microcystins. Toxicon. 40:1115-1120.

Metcalf JS, Meriluoto JAO, Codd GA (2006). Legal and security requirements for the air transportation of cyanotoxins and toxigenic cyanobacterial cells for legitimate research and analytical purposes. Toxicol Lett. 163:85-90.

Metcalf JS, Young FM, Codd GA (2017) Performance assessment of a cylindrospermopsin ELISA with purified compounds and cyanobacterial extracts. Environ Forensics 18:147-152.

Nałęcz-Jawecki G, Tarczyńska M, Sawicki J (2002). Evaluation of the toxicity of cyanobacterial blooms in drinking water reservoirs with microbiotests. Fresenius Environ Bull. 11:347-351.

Norris RL, Seawright AA, Shaw GR, Smith MJ, Chiswell RK, Moore MR (2001). Distribution of ${ }^{14} \mathrm{C}$ cylindrospermopsin in vivo in the mouse. Environ Toxicol. 16:498-505.

Oberemm A, Becker J, Codd GA, Steinberg C (1999). Effects of cyanobacterial toxins and aqueous crude extracts of cyanobacteria on the development of fish and amphibians. Environ Toxicol. 14:77-88.

OECD (1997). Test No. 471: bacterial reverse mutation test. Guidelines for the testing of chemicals. Paris: Organisation for Economic Cooperation and Development. https://read.oecd-ilibrary.org/environment/.

OECD (2004). Test No. 202: Daphnia acute immobilisation test and reproduction test. Guidelines for the testing of chemicals. Paris: Organisation for Economic Cooperation and Development. https://read.oecd-ilibrary.org/environment/.

OECD (2011). Test No. 456: H295R steroidogenesis assay. Guidelines for the testing of chemicals. Paris: Organisation for Economic Cooperation and Development. https://read.oecd-ilibrary.org/environment/.

OECD (2012). Test No. 211: Daphnia magna reproduction test. Guidelines for the testing of chemicals. Paris: Organisation for Economic Cooperation and Development. https://read.oecd-ilibrary.org/environment/.

OECD (2013). Test No. 236: Fish Embryo Acute Toxicity (FET) test. Guidelines for the testing of chemicals. Paris: Organisation for Economic Cooperation and Development. https://read.oecd-ilibrary.org/environment/.

OECD (2016a). Test No. 455: performance-based test guideline for stably transfected transactivation in vitro assays to detect estrogen receptor agonists and antagonists. Guidelines for the testing of chemicals. Paris: Organisation for Economic Cooperation and Development.

OECD (2016b). Test No. 458: stably transfected human androgen receptor transcriptional activation assay for detection of androgenic agonist and antagonist activity of chemicals. Guidelines for the testing of chemicals. Paris: Organisation for Economic Cooperation and Development. https://read.oecd-ilibrary.org/ environment/. 
OECD (2016c). Test No. 476: in vitro mammalian cell gene mutation test. Guidelines for the testing of chemicals. Paris: Organisation for Economic Cooperation and Development. https://read.oecd-ilibrary.org/environment/.

OECD (2016d). Test No. 487: in vitro mammalian cell micronucleus test. Guidelines for the testing of chemicals. Paris: Organisation for Economic Cooperation and Development. https://read.oecd-ilibrary.org/environment/.

Okumura DT, Sotero-Santos RB, Takenaka RA, Rocha O (2007). Evaluation of cyanobacteria toxicity in tropical reservoirs using crude extracts bioassay with cladocerans. Ecotoxicology. 16:263-270.

Oshima Y (1995). Postcolumn derivatization liquid chromatographic method for paralytic shellfish toxins. J AOAC Int. 78:528-532.

Palíková M, Krejčí R, Hilscherová K, Babica P, Navrátil S, Kopp R et al. (2007a). Effect of different cyanobacterial biomasses and their fractions with variable microcystin content on embryonal development of carp (Cyprinus carpio L.). Aquat Toxicol. 81:312-318.

Palíková M, Krejčí R, Hilscherová K, Burýšková B, Babica P, Navrátil S et al. (2007b). Effects of different oxygen saturation on activity of complex biomass and aqueous crude extract of cyanobacteria during embryonal development in carp (Cyprinus carpio L.). Acta Veterinaria Brno. 76:291-299.

Palus J, Dziubałtowska E, Stańczyk M, Lewińska D, Mankiewicz-Boczek J, Izydorczyk $\mathrm{K}$ et al. (2007). Biomonitoring of cyanobacterial blooms in Polish water reservoir and the cytotoxicity and genotoxicity of selected cyanobacterial extracts. Int J Occup Med Environ Health. 20:48-65.

Papageorgiou J, Nicholson BC, Linke TA, Kapralos C (2005). Analysis of cyanobacterial-derived saxitoxins using high-performance ion exchange chromatography with chemical oxidation/fluorescence detection. Environ Toxicol. 20:549-559.

Patlewicz G, Simon TW, Rowlands JC, Budinsky RA, Becker RA (2015). Proposing a scientific confidence framework to help support the application of adverse outcome pathways for regulatory purposes. Regul Toxicol Pharmacol. 71:463-477.

Pekar H, Westerberg E, Bruno O, Lääne A, Persson KM, Sundström LF et al. (2016). Fast, rugged and sensitive ultra high pressure liquid chromatography tandem mass spectrometry method for analysis of cyanotoxins in raw water and drinking water-first findings of anatoxins, cylindrospermopsins and microcystin variants in Swedish source waters and infiltration ponds. J Chromatogr A. 1429:265-276.

Pflugmacher S, Wiegand C, Beattie KA, Krause E, Steinberg CEW, Codd GA (2001). Uptake, effects, and metabolism of cyanobacterial toxins in the emergent reed plant Phragmites australis (cav.) trin. ex steud. Environ Toxicol Chem. 20:846-852.

Pichardo S, Cameán AM, Jos A (2017). In vitro toxicological assessment of cylindrospermopsin: a review. Toxins. 9:402.

Portmann C, Blom JF, Gademann K, Jüttner F (2008). Aerucyclamides A and B: isolation and synthesis of toxic ribosomal heterocyclic peptides from the cyanobacterium Microcystis aeruginosa PCC 7806. J Nat Prod. 71:1193-1196.

Prieto AI, Guzmán-Guillén R, Díez-Quijada L, Campos A, Vasconcelos V, Jos Á et al. (2018). Validation of a method for cylindrospermopsin determination in vegetables: application to real samples such as lettuce (Lactuca sativa L.). Toxins. 10:63. 
Sassolas A, Catanante G, Fournier D, Marty JL (2011). Development of a colorimetric inhibition assay for microcystin-LR detection: comparison of the sensitivity of different protein phosphatases. Talanta. 85:2498-2503.

Scherer M, Bezold D, Gademann K (2016). Investigating the Toxicity of the Aeruginosin Chlorosulfopeptides by Chemical Synthesis. Ang Chem Int Ed. 55:9427-9431.

Schroeder AL, Ankley GT, Houck KA, Villeneuve DL (2016). Environmental surveillance and monitoring - The next frontiers for high-throughput toxicology. Environ Toxicol Chem. 35:513-525.

Shoemaker J, Dietrich W (2017). Single laboratory validated method for determination of cylindrospermopsin and anatoxin-a in ambient water by liquid chromatography/tandem mass spectrometry (LC/MS/MS). Washington (DC): United States Environmental Protection Agency; Office of Research and Development. https://cfpub.epa.gov/si/index.cfm.

Shoemaker J, Tettenhorst D, De la Cruz A (2015). Method 544: Determination of microcystins and nodularin in drinking water by solid phase extraction and liquid chromatography/tandem mass spectrometry (LC-MS/MS). Washington (DC): Environmental Protection Agency of the United States:70 pp. EPA/600/R-14/474.

Sieroslawska A (2013). Evaluation of the sensitivity of organisms used in commercially available toxkits to selected cyanotoxins. Polish J Environ Stud. 22.

Sotero-Santos RB, Silva CRDSE, Verani NF, Nonaka KO, Rocha O (2006). Toxicity of a cyanobacteria bloom in barra bonita reservoir (middle tiete river, Sao Paulo, Brazil). Ecotoxicol Environ Safety. 64:163-170.

Stewart I, Carmichael WW, Sadler R, McGregor GB, Reardon K, Eaglesham GK et al. (2009). Occupational and environmental hazard assessments for the isolation, purification and toxicity testing of cyanobacterial toxins. Environ Health. 8:52.

Štraser A, Filipič M, Žegura B (2011). Genotoxic effects of the cyanobacterial hepatotoxin cylindrospermopsin in the HepG2 cell line. Arch Toxicol. 85:1617-1626.

Štraser A, Filipič M, Žegura B (2013). Cylindrospermopsin induced transcriptional responses in human hepatoma HepG2 cells. Toxicol in Vitro. 27:1809-1819.

Tarczyńska M, Nałẹcz-Jawecki G, Brzychcy M, Zalewski M, Sawicki J (2000). The toxicity of cyanobacterial blooms as determined by microbiotests and mouse assays. In: Persoone G, Janssen C, De Coen W, editors: New microbiotests for routine toxicity screening and biomonitoring. New York: Kluwer Academic:527-532.

Tarczyńska M, Nalecz-Jawecki G, Romanowska-Duda Z, Sawicki J, Beattie K, Codd G et al. (2001). Tests for the toxicity assessment of cyanobacterial bloom samples. Environ Toxicol. 16:383-390.

Testai E, Scardala S, Vichi S, Buratti FM, Funari E (2016). Risk to human health associated with the environmental occurrence of cyanobacterial neurotoxic alkaloids anatoxins and saxitoxins. Crit Rev Toxicol. 46:385-419.

Tong P, Shao Y, Chen J, He Y, Zhang L (2015). A sensitive electrochemical DNA biosensor for Microcystis spp. sequence detection based on an Ag@ Au NP composite film. Anal Meth. 7:2993-2999.

Törökné AK, László E, Chorus I, Fastner J, Heinze R, Padisák J et al. (2000a). Water quality monitoring by Thamnotoxkit $\mathrm{F}^{\mathrm{TM}}$ including cyanobacterial blooms. Wat Sci Technol. 42:381-385.

Törökné AK, László E, Chorus I, Sivonen K, Barbosa FA (2000b). Cyanobacterial toxins detected by Thamnotoxkit (a double blind experiment). Environ Toxicol. 15:549-553. 
Törökné AK, Vasdinnyei R, Asztalos M (2007). A rapid microbiotest for the detection of cyanobacterial toxins. Environ Toxicol. 22:64-68.

Tousova Z, Oswald P, Slobodnik J, Blaha L, Muz M, Hu M et al. (2017). European demonstration program on the effect-based and chemical identification and monitoring of organic pollutants in European surface waters. Sci Tot Environ. 601:1849-1868.

Triantis TM, Kaloudis T, Hiskia A (2017a). SOP16: determination of cylindrospermopsin in filtered and drinking water by LC-MS/MS. In: Meriluoto J, Spoof L, Codd GA et al., editors: Handbook of cyanobacterial monitoring and cyanotoxin analysis. Chichester: John Wiley \& Sons:400-404.

Triantis TM, Kaloudis T, Hiskia A (2017b). SOP17: solid-phase extraction of anatoxin-a from filtered and drinking water. In: Meriluoto J, Spoof L, Codd GA et al., editors: Handbook of cyanobacterial monitoring and cyanotoxin analysis. Chichester: John Wiley \& Sons:405-407.

Triantis TM, Kaloudis T, Zervou S-K, Hiskia A (2017c). SOP7: solid-phase extraction of microcystins and nodularins from drinking water. In: Meriluoto J, Spoof L, Codd GA et al., editors: Handbook of cyanobacterial monitoring and cyanotoxin analysis. Chichester: John Wiley \& Sons:354-357.

Turner AD, Hatfield RG, Maskrey BH, Algoet M, Lawrence J (2019). Evaluation of the new European Union reference method for paralytic shellfish toxins in shellfish: a review of twelve years regulatory monitoring using pre-column oxidation LC-FLD. TrAC Trends Anal Chem. 113:124-139.

Turner AD, McNabb PS, Harwood DT, Selwood AI, Boundy MJ (2015). Singlelaboratory validation of a multitoxin ultra-performance LC-hydrophilic interaction LC-MS/MS method for quantitation of paralytic shellfish toxins in bivalve shellfish. J AOAC Int. 98:609-621.

Turner AD, Waack J, Lewis A, Edwards C, Lawton L (2018). Development and single-laboratory validation of a UHPLC-MS/MS method for quantitation of microcystins and nodularin in natural water, cyanobacteria, shellfish and algal supplement tablet powders. J Chromatogr B. 1074:111-123.

UNECE (2017). Globally harmonized system of classification and labelling of chemicals (GHS), seventh edition. Geneva: United Nations Economic Commission for Europe. United Nations Publications:527 pp.

US EPA (2015). Method 545: determination of cylindrospermopsin and anatoxin-a in drinking water by liquid chromatography electrospray ionization tandem mass spectrometry (LC/ESI-MS/MS). Washington (DC): United States Environmental Protection Agency:27.

Van De Riet J, Gibbs RS, Muggah PM, Rourke WA, MacNeil JD, Quilliam MA (2011). Liquid chromatography post-column oxidation (PCOX) method for the determination of paralytic shellfish toxins in mussels, clams, oysters, and scallops: Collaborative study. J AOAC Int. 94:1154-1176.

Vasas G, Gáspár A, Surányi G, Batta G, Gyémánt G, Márta M et al. (2002). Capillary electrophoretic assay and purification of cylindrospermopsin, a cyanobacterial toxin from Aphanizomenon ovalisporum, by plant test (Blue-Green Sinapis Test). Anal Biochem. 302:95-103.

Vezie C, Benoufella F, Sivonen K, Bertru G, Laplanche A (1996). Detection of toxicity of cyanobacterial strains using Artemia salina and MicrotoxR assays compared with mouse bioassay results. Phycologia. 35:198-202. 
Vieth R (2007). Vitamin D toxicity, policy, and science. J Bone Miner Res. 22:V64-V68. Waack J (2017). Uptake and depuration of cyanotoxins in the common blue mussel Mytilus edulis. Aberdeen: Institution:374 pp.

Wang P-J, Chien M-S, Wu F-J, Chou H-N, Lee S-J (2005). Inhibition of embryonic development by microcystin-LR in zebrafish, Danio rerio. Toxicon. 45:303-308.

Welker M, Bickel H, Fastner J (2002a). HPLC-PDA detection of cylindrospermopsin opportunities and limits. Water Res. 36:4659-4663.

Welker M, Fastner J, Erhard M, von Döhren H (2002b). Application of MALDI-TOF MS in cyanotoxin research. Environ Toxicol. 17:367-374.

Welker M, Khan S, Haque MM, Islam S, Khan NH, Chorus I et al. (2005). Microcystins (cyanobacterial toxins) in surface waters of rural Bangladesh pilot study. J Water Health. 3:325-337.

Welker M, von Döhren H, Täuscher H, Steinberg CEW, Erhard M (2003). Toxic Microcystis in shallow lake Müggelsee (Germany) - dynamics, distribution, diversity. Arch Hydrobiol. 157:227-248.

Weller MG (2013). Immunoassays and biosensors for the detection of cyanobacterial toxins in water. Sensors. 13:15085-15112.

Wiese M, D’agostino PM, Mihali TK, Moffitt MC, Neilan BA (2010). Neurotoxic alkaloids: saxitoxin and its analogs. Mar Drugs. 8:2185-2211.

Wood SA, Biessy L, Puddick J (2018). Anatoxins are consistently released into the water of streams with Microcoleus autumnalis-dominated (cyanobacteria) proliferations. Harmful Algae. 80:88-95.

Žegura B (2016). An overview of the mechanisms of microcystin-LR genotoxicity and potential carcinogenicity. Mini Rev Med Chem. 16:1042-1062.

Žegura B, Sedmak B, Filipič M (2003) Microcystin-LR induces oxidative DNA damage in human hepatoma cell line HepG2. Toxicon. 41:41-48.

Žegura B, Štraser A, Filipič M (2011). Genotoxicity and potential carcinogenicity of cyanobacterial toxins - a review. Mutat Res, Rev Mutat Res. 727:16-41.

Žegura B, Volčič M, Lah TT, Filipič M (2008). Different sensitivities of human colon adenocarcinoma (CaCo-2), astrocytoma (IPDDC-A2) and lymphoblastoid (NCNC) cell lines to microcystin-LR induced reactive oxygen species and DNA damage. Toxicon. 52:518-525.

Zervou S-K, Christophoridis C, Kaloudis T, Triantis TM, Hiskia A (2017). New SPE-LC-MS/MS method for simultaneous determination of multi-class cyanobacterial and algal toxins. J Hazard Mat. 323:56-66.

Zhan L, Sakamoto H, Sakuraba M, Wu DS, Zhang LS, Suzuki T et al. (2004). Genotoxicity of microcystin-LR in human lymphoblastoid TK6 cells. Mutat Res-Genet Toxicol Environ Mutagen. 557:1-6.

Zhang W, Han C, Jia B, Saint C, Nadagouda M, Falaras P et al. (2017). A 3D graphenebased biosensor as an early microcystin-LR screening tool in sources of drinking water supply. Electrochimica Acta. 236:319-327. 